\title{
INTELLECTUAL PROPERTY RightS HiNDER SEQUENTIAL INNOVATION EXPERIMENTAL EVIDENCE
}

\author{
Julia Brüggemann a, , Paolo Crosetto b, Lukas Meub c, Kilian Bizer d \\ a, c, d Faculty of Economic Sciences, Chair of Economic Policy and SME Research, University \\ of Göttingen, Platz der Göttinger Sieben 3, 37073 Göttingen, Germany \\ ${ }^{\mathrm{b}}$ INRA UMR 1215, GAEL, Université de Grenoble, 38000 Grenoble, France
}

\begin{abstract}
In this paper we contribute to the discussion on whether intellectual property rights foster or hinder innovation by means of a laboratory experiment. We introduce a novel Scrabble-like word-creation task that captures most essentialities of a sequential innovation process. We use this task to investigate the effects of intellectual property allowing subjects to impose license fees on their innovations. We find intellectual property to have an adverse effect on welfare as innovations become less frequent and less sophisticated. Introducing communication among innovators does not reduce this detrimental effect. Introducing intellectual property results in more basic innovations, with subjects failing to exploit the most valuable sequential innovation paths. Subjects act more self-reliant and non-optimally in order to avoid paying license fees. Our results suggest that granting intellectual property rights hinders innovation, especially for sectors characterized by a strong sequentiality in innovation processes.
\end{abstract}

Keywords: innovation, intellectual property, laboratory experiment, real effort task, creativity JEL-Classification: C91, D89, P14

\section{Highlights:}

We examine innovation activity by a Scrabble-like creativity task in the lab.

We analyze two treatment conditions, namely a regime of IPR and communication. IPR enforced by license fees have a negative effect on innovation activity and welfare. Communication among innovators has no effect on the innovative activity.

\footnotetext{
* Corresponding author: Julia Brüggemann, julia.brueggemann@wiwi.uni-goettingen.de, phone: +49 55139 7761; fax: +495513919558.
} 


\section{Introduction}

The question whether to grant intellectual property (IP) rights to innovators has been widely discussed in economics, law and politics. ${ }^{1}$ Proponents of IP rights argue that temporary monopoly rights granted through patents or copyright provide incentives by protecting innovators from imitation and allotting to them a part of the social surplus generated by subsequent innovators (Arrow, 1962; Nordhaus, 1969; Scherer, 1972). Further, patents are assumed to induce disclosure of new technologies and therefore foster a swift and comprehensive diffusion of knowledge (Machlup, 1958). These traditional arguments have been increasingly put to question. Opponents of IP rights argue that the creation of monopolies on innovations increases prices, distorting resource allocations, causing inefficiencies and leading to welfare losses (Boldrin and Levine, 2013; Stiglitz, 2008). Moreover, too broad, too long, or too fragmented IP rights can give rise to gridlock and anticommons issues in downstream innovations (Heller and Eisenberg, 1998).

In this paper we contribute to the debate on the role of patents in the context of sequential innovation by means of a controlled real-effort laboratory experiment involving creativity. We introduce a novel design that allows us to create counterfactual situations and test directly the effects of IP rights on the innovation rate and welfare of a laboratory economy.

The issues of what are the optimal extent and nature of IP rights have been long debated, but neither theoretical nor empirical research has provided a final answer. Theoretical results cut both ways. Conventional wisdom is largely derived from static models, and does not robustly survive in dynamic, sequential innovation models that best describe sectors characterized by cumulative research (Scotchmer, 1991). Dynamic models offer a less positive view of the effect of IP on the rate of innovation and thus aggregate welfare. Green and Scotchmer (1995) study the division of profits between sequential innovators and suggest that it is desirable to minimize patent life. Moschini and Yerokhin (2008) analyze IP regimes with and without research exemptions. They find ambiguous effects and show that firms ex ante always prefer a full patent protection regime. In contrast, Bessen and Maskin (2009) implement a model with sequential and complementary innovations, finding that IP rights are welfare-reducing, and, in some cases, are not even preferred by the inventor, who favors instead to publicly disclose her innovations. Going a step further, Boldrin and Levine (2008) theoretically and empirically show that innovators can earn competitive rents even in complete absence of monopoly power. Hunt (2004) investigates the role of the patentability standard in a sequential innovation model in which profitability of inventions is eroded by new inventions.

\footnotetext{
${ }^{1}$ For a comprehensive literature review on theoretical aspects of patents see Gallini and Scotchmer (2002), Hall and Harhoff (2012), Denicolò (2008); for a review on central policy debates see Jaffe (2000).
} 
He finds an inverse U-shaped relationship between patentability standards and the rate of innovation. Using an asymmetric-ability multistage R\&D race model, Fershtman and Markovich (2010) find that the opportunity of licensing in a patent system might be superior to a system with strong patent rights. Summing up, the dynamic models focus on the trade-off between securing sufficient incentives to current and future inventors. The overall result of the theoretical analyses, though, seems to crucially depend on the assumptions of the respective model.

Empirical research also yields mixed evidence. Results on the impact of IP rights on innovativeness range from a positive influence (Ernst, 2001), an "inverted U" shaped relation (Aghion et al., 2005; Furukawa, 2007; Hashmi, 2013), a negligible impact (Dosi et al., 2006; Lerner, 2009) to a negative influence (Qian, 2007; Williams, 2013). ${ }^{2}$

Methodologically, both theoretical and empirical analyses are second-best with respect to the observation of a clean counterfactual situation. The absence of conclusive evidence might be due to the lack of natural experiments that could allow us to observe a counterfactual, nonexistent patent-free world (Hall and Harhoff, 2012; Sørensen et al., 2010).

In this paper we exploit the unique characteristic of laboratory experiments of allowing to easily build counterfactual situations while retaining control over several confounding factors. We recreate a sequential innovation setting similar to Bessen and Maskin (2009), which fits best to copyrighted non-rivalrous goods and the respective industries such as software and semiconductors. In the spirit of Scotchmer (2004) we use this setting to explore the effects of IP rights on innovativeness and welfare.

The advantages of the laboratory in terms of control come at a cost. The laboratory creates an artificial environment that might lack external validity. In bringing IP rights to the lab we hence face a trade-off between replicating the complex interactions of creative, sequential innovation industries and making the task manageable for an experimental session characterized by time and monetary restrictions. This basic trade-off has been tackled in various ways in the still sparse experimental literature in the economics of innovation and IP rights. A laboratory task adapted to analyze innovation should include the use of both financial and creative resources, and should recreate both the incentive structure and the uncertainty of actual innovation settings. Moreover, it should provide an innovation space that is countable, in order to allow the researchers to analyze the data quantitatively. These constraints have been usually met by developing search tasks over some large, multidimensional space unknown to the subjects but controlled by the experimenter (Buccafusco and Sprigman, 2010; Buchanan and Wilson, 2014; Cantner et al., 2009; Ederer

\footnotetext{
${ }^{2}$ Bessen and Meurer (2008) and Lanjouw and Lerner (2000) provide a review.
} 
and Manso, 2013; Meloso et al., 2009). Another set of papers has instead forfeited control over the results of the creation process to focus on creativity only (see, for instance, Buccafusco and Sprigman, 2010, who let the subjects write poems). Toubia (2006) is, to the best of our knowledge, the only paper implementing a sequential 'ideation' task that requires creativity and provides some sort of countable space in which different incentive schemes for creativity can be studied.

To achieve a reasonable balance, and include both dynamics and creativity, we employ the design of Crosetto (2010) and develop a Scrabble-like word-creation task. The task involves creative use of scarce resources (letters) over a known but vast space (all the existing words), thus at the same time implementing creative effort and granting complete control of the results. We implement (strict) sequentiality by allowing only three-letter words to be created from individual letters, while longer words have to be built extending shorter ones, one letter at a time. Subjects are rewarded for creating words. Additionally, in some treatments subjects have to license, for a fee, their words and extensions to other subjects to serve as base for extensions in further periods.

Within this artificial but rich setting we implement two treatments, across subjects. First, we directly test the effects of IP rights on innovativeness and welfare by imposing two alternative IP regimes: a no-IP regime, where all license fees are exogenously set to zero, and an IP regime in which license fees are determined endogenously by subjects for each newly created word. Second, we test the robustness of individual licensing behavior in the case of stronger social interaction, by enabling or not chat communication. We thus investigate whether communication among innovators builds up altruistic norms that foster cooperation and decrease overall license fees for innovations.

We find that the presence of IP rights results in less and less sophisticated innovations and significantly reduces total welfare by 20 to 30 percent. This is due to IP rights causing a shift in behavior from more valuable, longer words towards less valuable, shorter ones. Subjects, in their quest to avoid paying license fees, forego innovation opportunities that are instead seized in absence of IP rights. Chat communication reduces the overall level of license fees, but this does not affect the rate of innovation: the detrimental effect of introducing IP rights holds both with and without communication. 


\section{Experimental Design}

\subsection{Related experimental literature}

Experimenters trying to deal with intellectual property issues face two sets of problems when designing their tasks. First, they need to translate the idea of innovation in the lab. This means allowing the subjects to use both financial and creative resources, but within a task in which it is possible to accurately assess quality and quantity of the goods produced. Introducing creativity and skills is crucial to obtain external validity of the results; control is crucial to allow for treatment comparisons and to derive robust results. Second, they must recreate a multi-period dynamic landscape in a relatively short-lived experimental session.

In order to deal with these basic design problems a first group of experiments chooses to model the creative process using search over complex spaces. Subject explore the search space looking for some optimal solution that yields higher payoffs, and that the experimenter knows and controls. Often this optimal solution is randomly chosen by the experimenter over the space. Meloso et al. (2009) use a combinatorial task, with an optimal non-obvious solution, and find that participants disseminate intellectual discoveries better in a market than in a patent system. Cantner et al. (2009) model R\&D as a multidimensional search process with uncertainty, in which the best option is randomly determined. They investigate competition for innovation in a patent race scenario to classify investor types, finding that most subjects use objective investment criteria. Dimmig and Erlei (2013) use a similar task and show that the introduction of patenting has only a minor impact on R\&D behavior. Ederer and Manso (2013) use a search task in a multi-dimensional space. They find that a combination of tolerance for early failure and rewards for long-term success are most effective in fostering innovation. Buchanan and Wilson (2014) implement a search task that consists of creating colors with the aim of finding the 'color of the day', randomly set by the experimenter, and introduce trade. In their IP treatment the creation of non-rivalrous knowledge goods is highest; however, prices increase as substantial monopoly profits are acquired by the innovators. In the absence of IP, Buchanan and Wilson still identify the incentive to create non-rivalrous knowledge goods, but IP theft as well. They also implement chat communication among subjects to enable bargaining and cooperation.

By choosing to implement search tasks, the aforementioned experiments abstract away from the crucial features of creativity and individual skills. In some of the designs, finding the 'right' combination is just a matter of luck and enough trials. Innovations are usually not created through such a process. A smaller set of papers choose instead to implement outright "creative" tasks, i.e. tasks involving creative skills rather than the search of an often randomly 
chosen optimal solution. Buccafusco and Sprigman (2010) ask their subjects to write poems and subsequently implement a market for them. They find that the preferences of IP creators, owners, and purchasers are unstable and dependent on the initial distribution of IP rights, and that there is a substantial valuation asymmetry between creators and purchasers of IP, similar to the well-known endowment effect. Such designs capture the creativity core of innovations better, but forfeit control - it is impossible to accurately assess which poem is 'better' or 'more creative' in the set.

In this paper we develop a task that integrates both creativity and control of the outcome. We employ a Scrabble-like real effort word creation game originally introduced by Crosetto (2010). In this task subjects innovate over a familiar space (their language), using both economic (experimental money) and cognitive (creative effort) resources. The production process requires creativity and skill, but its results are countable and can be used to create precise statistics and comparisons across conditions. By allowing subjects to extend already created words, we induce sequentiality and dynamics in an intuitive way. Our approach is similar to Toubia (2006). In his 'ideation game' subjects are faced with complex problems (i.e., "How can the impact of the U.N. Security Council be increased") and must come up with ideas. Ideas can be 'new' or build on an existing idea, thus introducing sequentiality. The value of ideas is a function of the incentive scheme introduced. The game implements different incentive schemes, including a flat condition, in which subjects are paid for participation but ideas are worthless in themselves, a piece-rate condition in which each idea was worth one token, and a citation condition, in which ideas that are more built upon and extended are more valuable. Differently from Toubia (2006), our experiment allows for an evaluation of the output of the innovation process (in our case, words) that is independent of the incentive scheme adopted; words are valued according to an objective Scrabble-like rule assigning value to each letter, thus allowing to assess the total production of the economy by an objective standard known to all participants.

\subsection{Design}

Our experimental design is inspired by the board game Scrabble with the addition of a price on letters, strict sequentiality in word creation and IP rights on created words. Buying letters is a risky investment, and sequentiality and IP rights add a strategic dimension to the game.

The task of the subjects is to create words. They do so by using letters, which they buy from the experimenter. Each word produced generates an immediate payoff that corresponds to the sum of the values of the letters used in the respective word. This value is the same as in 
Scrabble, roughly determined by the inverse of a letter's absolute number in the set. For example, an $a$ is worth 1 , a $b 3$, an $x 8 .^{3}$

There are two types of words in the experiment. With the letters they own, subjects can either form a three-letter word (we call it a root), or extend existing words (an extension). Roots can be produced with any three letters, as long as the word exists. For example, with $t, r$ and $a$, a subject can produce art or rat. Extensions are generated by adding one letter in any position of a word: for instance, cat can be extended into cart, or cats, or chat. ${ }^{4}$ Extensions can be further extended as long as the language allows: for instance, cart can be further extended into chart, and chart into charts. Roots can be used to generate alternative extension paths, and the amount of possible extensions stemming from each word is usually long and branched. We hence implement in our experiment a required inventive step of three letters for new inventions, and one letter for marginal innovations. Table 1 shows all the extension paths of cat, along with their value.

It is clear from table 1 that longer words tend to yield higher payoffs. Extensions are more profitable than roots, rewarding the extender with the full value of the word extended and not just with the value of his marginal contribution. For example, extending cat into cart costs the subject the letter $r$, worth 1 token, and yields a payoff of 6 tokens. To keep the experiment simple and manageable we rule out technological obsolescence: the full value of the extended word is transferred to the extension, with no discounting.

This structure allows us to introduce intellectual property rights over the sequence of innovations in a simple and intuitive way by allowing the subjects to impose a license fee on the use of their created word for extensions. Roots cannot be copied - i.e., we impose copyright on the 3-letter innovations. License fees can be applied only to the use of roots to generate extensions. This eliminates incentive problems on roots, and allows us to focus on the issue of the split of IP rights between the upstream and downstream innovators in a sequence. While licensing is compulsory - subjects do not have the right to exclude others from extending their words - through this fee subjects can secure part of (or all) the surplus created in extending for themselves. The surplus is generated by reusing the same resources, i.e. letters. We let subjects choose the level of the fee as a percentage, from 0 to $100 \%$, of the value of the licensed word. In the example, the owner of cat (value 5) can choose to impose a fee that ranges from 0 to 5 tokens to the subject that wishes to extend cat into cart. License

\footnotetext{
${ }^{3}$ The details of the letter set used are given in appendix B, together with the English translation of the original experimental instructions.

${ }^{4}$ For the sake of clarity, all examples are reported in English, even if the actual experiment was run in German. While the actual words that can be created vary across languages, the basic rules and the ideas behind the examples are general.
} 
fees enable us to address in a simple way the central problem in sequential IP rights, the split of profits between upstream and downstream innovators (Scotchmer, 1991).

Table 1. All allowed extension paths of cat

\begin{tabular}{|c|c|c|c|c|c|}
\hline \multirow{2}{*}{ root } & \multicolumn{5}{|c|}{ extensions } \\
\hline & +1 & +2 & +3 & +4 & +5 \\
\hline \multirow{7}{*}{ cat (5) } & cant (6) & $\begin{array}{l}\text { canst }(7) \\
\text { canto }(7) \\
\text { cants }(7)\end{array}$ & $\begin{array}{c}\text { canton }(8) \\
\text { cantor }(8) \\
\text { cantons }(8)\end{array}$ & $\begin{array}{l}\text { cantons }(9) \\
\text { cantors }(9)\end{array}$ & \\
\hline & capt (8) & & & & \\
\hline & cart (6) & $\begin{array}{l}\text { carat }(7) \\
\text { caret }(7) \\
\text { carts }(7)\end{array}$ & $\begin{array}{c}\text { carats }(8) \\
\text { carets }(8) \\
\text { carpet }(10) \\
\text { claret }(8)\end{array}$ & $\begin{array}{c}\text { carpets }(11) \\
\text { clarets }(9)\end{array}$ & \\
\hline & $\begin{array}{l}\text { cast (6) } \\
\text { cats (6) }\end{array}$ & $\begin{array}{l}\text { caste }(7) \\
\text { casts }(7)\end{array}$ & $\begin{array}{l}\text { caster }(8) \\
\text { castes }(8) \\
\text { castle }(8)\end{array}$ & $\begin{array}{c}\text { casters }(9) \\
\text { castled }(10) \\
\text { castles }(9) \\
\text { coaster }(9)\end{array}$ & coasters $(10)$ \\
\hline & chat (9) & $\begin{array}{l}\text { chant (10) } \\
\text { chart (10) } \\
\text { chats (10) } \\
\text { cheat (10) }\end{array}$ & $\begin{array}{l}\text { chants (11) } \\
\text { charts (11) } \\
\text { chaste (11) } \\
\text { cheats (11) }\end{array}$ & $\begin{array}{l}\text { chasten (12) } \\
\text { chastes (12) }\end{array}$ & chastens (13) \\
\hline & coat (6) & $\begin{array}{l}\text { coast }(7) \\
\text { coats }(7)\end{array}$ & coasts $(8)$ & & \\
\hline & scat (6) & $\begin{array}{l}\text { scant }(7) \\
\text { scats }(7)\end{array}$ & $\begin{array}{c}\text { scants (8) } \\
\text { scanty (11) } \\
\text { secant (8) }\end{array}$ & $\begin{array}{c}\text { scantly (12) } \\
\text { secants (9) }\end{array}$ & scantily (13) \\
\hline
\end{tabular}

\subsubsection{Treatments}

We implement two different treatments over this basic structure, in a factorial $2 \times 2$ betweensubjects design. First, we manipulate exogenously the presence or absence of intellectual property rights. In the Intellectual Property $(I P)$ treatments, subjects can impose a license fee on the access to their words to others. In noIP treatments, this is not possible, and all words are publicly available at no extra fee. noIP treatments are equivalent to exogenously setting all license fees to $0 \%$. We can thus directly test the effect of IP rights on the rate of word creation and hence on payoffs at the individual and group levels.

Second, we manipulate the possibility for subjects to communicate with each other. In chat treatments we introduce a chat box in which subjects can communicate with all others in their group. In noChat treatments subjects cannot communicate. These treatments allow us to observe the effect of communication, a recurring results of voluntary contribution and public 
good experiments in the laboratory (Bochet et al., 2006; Krishnamurthy, 2001; Oprea et al., 2014), on cooperation, and hence possibly improve innovation performance.

\subsubsection{Design details}

The game is played by randomly matched groups of 4 subjects. The composition of groups is constant during the whole game. Within groups, subjects play sequentially, as in turn-based games. ${ }^{5}$ Subjects start the experiment with an endowment of 75 tokens ( 1 token converts to $€ 0.12$, so that the initial endowment is of €9) and 4 randomly pre-assigned letters. The experiment lasts for 25 periods. In each period, each subject has to make at most three choices: an investment decision, a production choice and, in IP treatments only, an intellectual property decision.

\section{Investment}

Subjects buy a letter at a fixed price of 2 tokens. Letters are randomly drawn from the letter set. The random sequence governing letter draws is predetermined and fixed, though unknown to the subjects, in order to make results from different groups and treatments fully comparable. The average value of a drawn letter is 1.87 , so that the price is slightly above the expected value, which makes buying a letter a risky investment with potentially negative returns. Subjects can skip the investment phase and choose not to buy any letter.

\section{Production}

Subjects are then given the opportunity to produce a word. They can create a new three-letter word (a root), extend an existing word by adding exactly one letter in any position (an extension), or do not produce anything and pass.

All submitted roots or extensions are spellchecked by the system. Moreover, to give stronger incentives to be creative, subjects are not allowed to submit a word previously created by other subjects. All validly created words enter a public word repository that each subject has at the center of its screen at any time. The list of existing words can be sorted alphabetically or by word length, value, and, for IP treatments, word owner and license fee attached to the word.

\footnotetext{
${ }^{5}$ Synchronous decisions have been ruled out both for reasons of software complexity and in order to avoid issues of coordination, duplicated words and time pressure.
} 


\section{Intellectual Property}

In $I P$ treatments subjects who produced a word (root or extension alike) in the period are asked to set a license fee for the newly-created word. Subjects submit their choice using a line of radio buttons consisting of 11 discrete values, ranging from $0 \%$ to $100 \%$ in steps of $10 \%$, with no default value selected. Subjects can impose license fees only to their marginal contribution to the word created. In the case of a root, license fees are imposed on the whole three-letter word. In the case of an extension, the license fee is imposed only on the added letter. Subjects are not allowed to keep their word for themselves - licensing is compulsory. This grants us more control, allowing us to rule out heterogeneous abilities and attitudes in negotiating over license fees.

Let us work out an example. Subject A creates cat, a root of value 5, and imposes a license fee of $60 \%$. Subject B then extends cat into chat. Accordingly, subject B has to pay a license fee of 3 tokens ( 5 times 0.6 ) to subject A for using cat, but can in turn impose a license fee on her marginal contribution to the word, the letter $h$. Her payoff for creating chat is the value of chat ( 9 tokens) minus the fee paid ( 3 tokens) and it is hence 6 . If subject B sets a license fee $80 \%$ on $h$ (the value of $h$ is 4 ), then a potential extender of chat will have to pay 3 tokens to subject A and $3.2(80 \%$ of $h$ 's 4$)$ to subject B. All these computations are automatically performed by the computer that allocates license fees to the respective marginal contributors. By imposing license fees on words, subjects can gain additional revenue, when their words are extended by others. However, on the group level, license fees are nothing but a zero-sum mechanism to redistribute wealth as there are no transaction costs.

\section{Idle phase}

When it is not their turn, subjects face the main board of the game. ${ }^{6}$ Here they can keep track of their earnings, follow what other subjects are doing, inspect and sort the list of words created, and use an interactive spellchecker for free. ${ }^{7}$

In chat treatments, the main board incorporates a chat box where subjects can communicate with each other. Messages sent to the chat box are instantaneously visualized by all the other 3 subjects in the group.

\footnotetext{
${ }^{6} \mathrm{~A}$ screenshot of the main board can be found in the instructions in appendix B.

${ }^{7}$ The spellchecker has been provided to enable the subjects to explore the space of words and make individual skills less prominent. The spellchecker is based on the system's internal dictionary - in our case, the standard Windows dictionary for German.
} 


\subsection{Theoretical properties of the design}

Our design aims at recreating in the lab a sequential, cumulative innovation setting inspired by the models of Scotchmer (2004) and most closely Bessen and Maskin (2009). In particular, we induce strict sequentiality, since each extension is created from an existing word by adding one and only one letter.

We translate the concept of innovation in the lab by letting subjects be creative within a familiar space that is vast but intuitively searchable. Moreover, the space is countable, as it resides totally within the chosen dictionary. Every word that can be created according to our rules is fully described by two dimensions: its value that is translated in immediate payoff at the moment of creation and its extendibility. For each root we computed the number and value of all possible extensions. Recursively, we did the same for each extension. We hence have a precise and complete map of the innovation space facing our subjects.

Creating extensions requires effort and the presence of roots to be extended, but the reward is higher. This models the effort needed to invent in a natural way: generating complex ideas requires both effort and the ability to stand on the shoulders of giants. Our payoff structure implements constant returns to innovations. That is, an extension is worth exactly its marginal contribution (the added letter) plus the value of the root it is using. Absent any way to transfer the value of the root back to the root creator, in the form of license fees or citations (Hall et al., 2005) (in noIP treatments) then extensions are a much better deal than roots. This payoff structure best describes the situation of basic science - in which the first contributions lay down the foundations, allowing subsequent contributions to carry most of the value - or in the software industry - in which modern software technologies are built on thousands of algorithms, hardware, drivers, etc. that have been accumulated over the years.

Moreover, our experiment includes a key feature of technology markets: the fact that “imitators do not produce direct 'knockoffs,' but rather differentiated products. [... T] he different R\&D paths behind these products permit innovative complementarities. Imitation then increases the 'biodiversity' of the technology [...], improving prospects for future innovation" (Bessen and Maskin, 2009, p. 613). Extensions not only incorporate the existing root, but enlarge it in different directions, increasing the 'biodiversity' and opening up paths for future extensions. Discoveries work through improvement rather than replacement.

As in Bessen and Maskin (2009) innovations in our experiment are complementary. Each innovator can take a different research line, i.e. produce different words given the same letters, or strike a different deal between value and extension potential, and thus enhance the probability that more sophisticated products are created. 
A further characteristic of our experiment might drive part of the results. In noIP the optimal choice for the individual and for the group correlate more strongly than in $I P$ treatments. This is one of unavoidable consequences of having $I P$ rights in an economy and in the experiment as license fees are merely redistributing income, which affects optimal individual but not optimal collective choices as measured by the income of the aggregate group level. Differences across treatments might partially be ascribed to this effect. Nonetheless, our design allows us to control and minimize this problem. For each choice by each subject along the course of the game we can compute the individually optimal choice, and see how much the actual choice deviates from it. By analyzing this relative rather than absolute performance, we can produce results that are robust to the extent of the collective action problem.

\subsection{Testable hypotheses}

What is the effect of IP rights on innovation?

Our IP treatments are designed to provide an experimental answer to this question. In our task, overall welfare depends on the relative number of extensions built per each root. Since the expected net value of buying one letter is negative (the expected value of randomly drawing a letter is 1.87 for a cost of 2), a group only producing roots will face a decline in welfare, as compared to the initial endowment. Extensions allow groups to use their resources (letters) several times, producing net welfare gains as investment costs are sunk.

In $I P$ treatments the presence of license fees affects the allocation of the surplus generated by extensions between the upstream and the downstream inventors. IP rights give incentives to innovate, but at the same time impose costs on downstream innovators, and hence act as a brake on the creation of more complex, derivative inventions. As in Scotchmer (1991), the effect of IP rights on overall welfare are hence ex-ante ambiguous, and we do not posit a specific hypothesis on the matter.

\section{What is the effect of communication on innovation?}

We further investigate the individual motivation in contributing to sequential innovation. Based on the findings of the public goods literature, where communication leads to more cooperation (see, among others, Bochet et al., 2006; Krishnamurthy, 2001; Oprea et al., 2014) and the studies pointing to high altruistic contributions in open innovative communities (Lakhani and Hippel, 2003), we expect communication to have a positive effect on the innovation rate. We therefore expect communicating subjects to build up group norms of low overall license fees. If, on top of this, lower fees lead to an increase in the number of 
extensions for each root, then we should observe more sophisticated innovations and higher profits in chat groups.

Which level of license fee will prevail in the long run?

In IP treatments, in which subjects are free to set their preferred license fee, our task replicates a social dilemma situation. Setting low or no license fees increases the chances of collectively reaching longer, profitable words, providing a public benefit; higher fees, on the other hand, are likely to generate higher private returns. In this context setting low fees can be interpreted as cooperation, since it potentially boosts the group's overall welfare.

Moreover, robust evidence from public good games hints at decreasing levels of cooperation over repetitions of the game (see, for instance, Croson, 2007; Fischbacher and Gächter, 2010). As in public good games, we therefore expect subjects to impose increasing license fees as the game proceeds; we also expect the level and rate of increase to be lower in chat treatments, in which cooperation is facilitated.

\subsection{Experimental procedures}

Experiments were conducted in the Laboratory for Behavioral Economics at the University of Göttingen in August and September 2013. The experimental software was written in python (Crosetto, 2010) . Participants were recruited with ORSEE (Greiner, 2004). We recruited 214 participants. Prior to the experiment, participants were exposed to a language-test to ensure a full working knowledge of German. ${ }^{8} 22$ subjects failed the test and had to be excluded from participation. The remaining 192 participants took part in 18 sessions of the experiment.

We implemented a pure between, $2 \times 2$ factorial design, crossing the dimensions chat/noChat and $I P / n o I P$. Subjects were allocated to 48 groups of 4 players, 12 for each treatment as summarized in table 2.

Table 2. Overview of the treatment conditions

\begin{tabular}{lcc}
\hline & no communication & communication \\
\hline no IP & noChat $/$ noIP & chat $/$ noIP \\
& $(\mathrm{N}=48)$ & $(\mathrm{N}=48)$ \\
IP - endogenous license fee & noChat $/ I P$ & chat $/$ noIP \\
& $(\mathrm{N}=48)$ & $(\mathrm{N}=48)$ \\
\hline
\end{tabular}

\footnotetext{
${ }^{8}$ The test was developed by Kirchkamp and Reiß (2011). The participants had to find the correct words or forms to complete sentences in a German text.
} 
Once allowed to participate, and before the start of the main task, subjects went through an incentivized word-finding control task..$^{9}$ At the end of the 25 periods of the main task, and after being notified their final score and payoff, participants were asked to complete a short questionnaire, including demographics, controls for language skills, familiarity with word tasks, and risk aversion. Overall participants were 24.1 years old and 53.6\% were female. Sessions lasted around 90 minutes. The 192 participants earned $€ 16.19$ on average, with a minimum payoff of $€ 7.1$ and a maximum of $€ 28.5$.

\section{Results}

In this section, we first report treatment effects, analyzing the impact of both the $I P$ and chat manipulations on the total number, quality and value of created words. Since the game is path-dependent, we then test the robustness of our findings by controlling for the actual decision sets faced by each subject at each decision. We then turn to the individual and group level, and run regressions to check if results survive when group and individual heterogeneity are taken into account. The focus on individual choices allows us to check to what extent subjects acted consistently with individual, or group payoff maximization, thus shedding light on the collective action problem more pronounced in in $I P$ treatments. Finally, we analyze the prevailing levels of license fees, their dynamics, and if their level impacts the innovation rate.

\subsection{Aggregate results: words and value created}

We first test if and to what extent the aggregate output created in our experiment is affected by the presence of IP rights and communication. To measure output we use the total net value created in each group, i.e., the value of all the words created, minus the cost of the letters used to create them.

Table 3 summarizes the core results on words and net value created. In the table, the total amount of letters bought represents the level of investment in the group. The average word length, together with the average word value, measure the degree of sophistication reached. The number of roots and extensions measures the share of base and follow-up inventions, respectively. All measures are calculated at the group level.

\footnotetext{
${ }^{9}$ The task was adapted from Eckartz et al. (2012). For details see appendix A.
} 
Table 3. Overview of words and value created by treatment

\begin{tabular}{|c|c|c|c|c|c|}
\hline & & noChat/noIP & noChat/IP & chat/noIP & chat/IP \\
\hline letters bought & mean $(\mathrm{sd})$ & $\begin{array}{c}85.5 \\
(7.51)\end{array}$ & $\begin{array}{c}84.3 \\
(8.05)\end{array}$ & $\begin{array}{c}80 \\
(9.16)\end{array}$ & $\begin{array}{l}81.42 \\
(7.43)\end{array}$ \\
\hline \multirow[t]{4}{*}{ total net value } & mean $(\mathrm{sd})$ & $\begin{array}{l}288.25 \\
(44.21)\end{array}$ & $\begin{array}{l}204.92 \\
(46.23)\end{array}$ & $\begin{array}{l}252.42 \\
(76.51)\end{array}$ & $\begin{array}{c}189.17 \\
(56.26)\end{array}$ \\
\hline & median & 295.5 & 210 & 235.5 & 209 \\
\hline & $\min$ & 200 & 103 & 155 & 99 \\
\hline & $\max$ & 350 & 274 & 404 & 280 \\
\hline word length & mean $(\mathrm{sd})$ & $\begin{array}{c}4.97 \\
(.3756)\end{array}$ & $\begin{array}{c}4.49 \\
(.3219)\end{array}$ & $\begin{array}{c}4.84 \\
(.4103)\end{array}$ & $\begin{array}{c}4.37 \\
(.3573)\end{array}$ \\
\hline word value & mean $(\mathrm{sd})$ & $\begin{array}{c}7.62 \\
(.5507)\end{array}$ & $\begin{array}{c}6.62 \\
(.3730)\end{array}$ & $\begin{array}{c}7.31 \\
(.6985)\end{array}$ & $\begin{array}{c}6.66 \\
(.6741)\end{array}$ \\
\hline no. extensions & mean $(\mathrm{sd})$ & $\begin{array}{l}49.33 \\
(5.76)\end{array}$ & $\begin{array}{l}43.33 \\
(6.21)\end{array}$ & $\begin{array}{l}45.33 \\
(8.11)\end{array}$ & $\begin{array}{c}38.5 \\
(7.54)\end{array}$ \\
\hline no. roots & mean $(\mathrm{sd})$ & $\begin{array}{l}10.92 \\
(1.98)\end{array}$ & $\begin{array}{c}13 \\
(2.22)\end{array}$ & $\begin{array}{l}10.67 \\
(2.61)\end{array}$ & $\begin{array}{l}14.25 \\
(2.60)\end{array}$ \\
\hline $\begin{array}{l}\text { extensions per } \\
\text { root }\end{array}$ & mean $(\mathrm{sd})$ & $\begin{array}{c}4.69 \\
(1.219)\end{array}$ & $\begin{array}{l}3.41 \\
(.7384)\end{array}$ & $\begin{array}{c}4.58 \\
(1.604)\end{array}$ & $\begin{array}{l}2.81 \\
(.7846)\end{array}$ \\
\hline
\end{tabular}

\subsubsection{The effect of intellectual property rights}

We find that noIP treatments result in significantly higher total net value, with and without chat communication (Mann-Whitney-U test ${ }^{10}$ : for chat/IP and chat/noIP $\mathrm{z}=-1.675, \mathrm{p}=.094$; for noChat/IP and noChat/noIP $\mathrm{z}=-3.464, \mathrm{p}=.0005)$. The difference is rather large. In absence of property rights with (without) chat communication the average net value created is about $40 \%(33 \%)$ higher. The groups performing worst in the noIP treatments achieve a total net value that is $50 \%$ (100\% without chat) higher than the worst group of the IP treatments.

Figure 1 shows that the distribution of total net value across noIP groups dominates the one for the $I P$ groups, both within the chat and the noChat treatments.

\footnotetext{
${ }^{10}$ In the following referred to by "MWU".
} 
Figure 1. Total net value by treatment and group
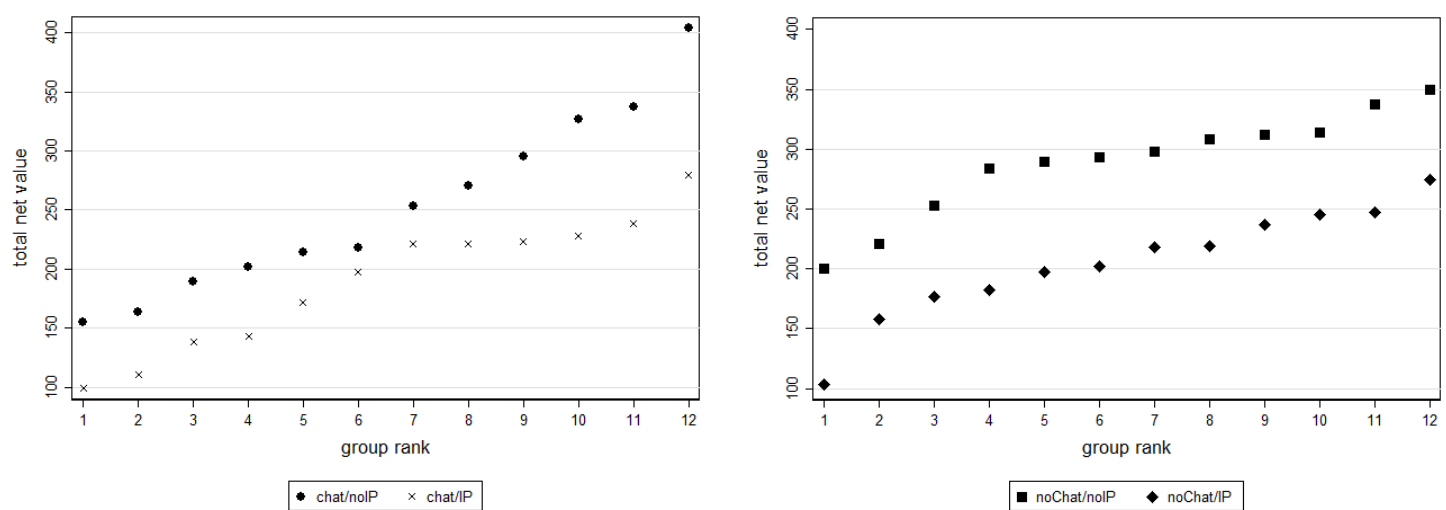

These striking differences are reflected in the characteristics of the words created. Without IP words are longer (MWU: for chat/IP and chat/noIP $\mathrm{z}=-2.483, \mathrm{p}=.013$; for noChat/IP and noChat/noIP $\mathrm{z}=-2.944, \mathrm{p}=.0032)$ and tend to be more valuable on average (MWU: for chat/IP and chat/noIP $\mathrm{z}=-1.559, \mathrm{p}=.119$; for noChat/IP and noChat/noIP $\mathrm{z}=-3.233, \mathrm{p}=.0012$ ). In contrast, the average investment is almost equal across treatments, as measured by the number of letters bought (MWU for chat/IP and chat/noIP $\mathrm{z}=0.521, \mathrm{p}=.6024$; for noChat/IP and noChat/noIP $\mathrm{z}=-0.406, \mathrm{p}=.6850)$.

RESULT 1: Introducing IP decreases overall welfare as a comparable level of investment is transformed into less sophisticated and less valuable innovations.

We now analyze what drives these treatment differences. Recall that a group as a whole does not bear any additional costs when building on existing roots or prior extensions, whereby the letters already used generate their inherent payoff again. Letters already bought can be seen as an endowment which was paid for beforehand, i.e. there are only sunk costs but potential gains in creating extensions. As a consequence, overall welfare increases with the relative number of extensions compared to roots.

Figure 2 shows the average over groups of the number of roots and extensions by treatment. There are substantial differences across treatments. In the IP treatments roots are built significantly more often relative to extensions. In chat/IP (noChat/IP) $71.1 \%$ (71.9\%) of created words are extensions, whereas in chat/noIP (noChat/noIP) the share is $79.3 \%$ (78.5\%). Both differences are statistically significant. Moreover, in the noIP treatments more extensions are created on average from each root (MWU: for chat/IP and chat/noIP $\mathrm{z}=-2.830$, $\mathrm{p}=.0047$; for noChat $/ I P$ and noChat $/$ noIP $\mathrm{z}=-2.688, \mathrm{p}=.0072$ ). Finally, not only in IP treatments subject created more roots, but these roots had a higher, though not significantly so, extendibility potential, that is, the value of all possible extensions path for each root (2632 
for $I P$ vs. 2374 for noIP). This is in line with intuition: in $I P$ treatments subjects had incentives to create more extendible roots since they could expect a higher stream of royalties. Despite this higher potential, in $I P$ treatments there were less extensions per root.

Figure 2. Number of roots and extensions created, by treatment (error bars show st.err. of the mean)

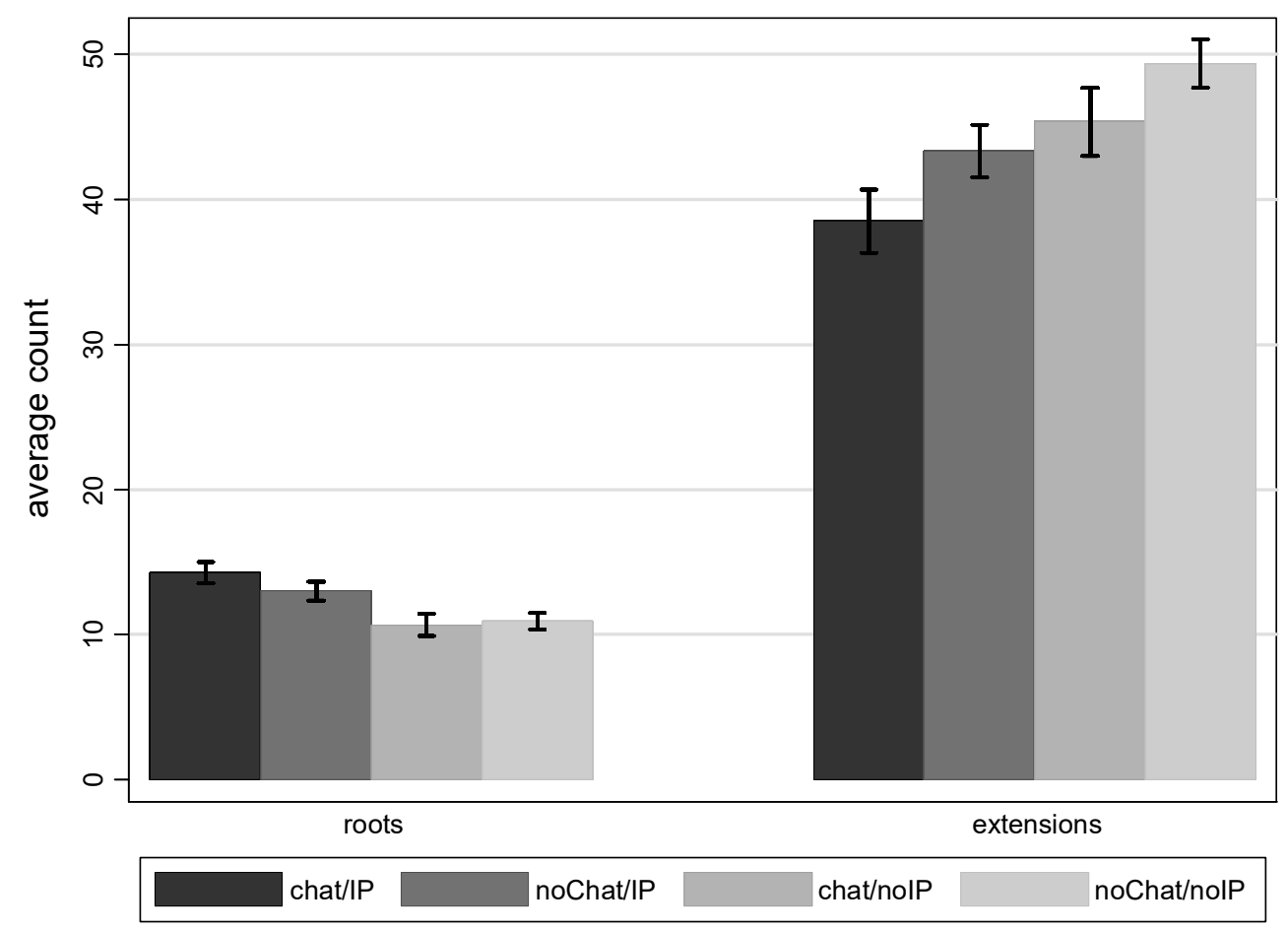

RESULT 2a: The deterioration in welfare due to introducing IP can partially be ascribed to a shift towards more basic innovations relative to the more sophisticated sequential ones.

We consider another channel through which IP rights could cause detrimental effects on total net value. Subjects might be characterized by a preference for their own creations. That is, they might refrain from extending words created by other players and restrict attention to their own. This might be due to an enhanced familiarity with one's own creations, or, in IP treatments, to avoid license fee payments. If this behavior emerges, profitable opportunities might be missed and the total net value of the group might end up being lower.

This behavior might stem from two different strategies. On the one hand, subjects might be rationally avoiding paying fees, and choose to create those words or extensions that give the highest payoff individually but not collectively. On the other hand, subjects might show an aversion to license fees even when paying a fee might be the individually optimal choice. In this paragraph, we restrict attention to the preference for own words, irrespective of the 
reason. We discuss the rationality of this behavior in section 3.3 below, where we analyze choices at the individual level.

We investigate the existence of a potential preference for own words by assigning an originator to each word. The originator is the subject who created the root for the respective word. ${ }^{11}$ Assuming an even distribution of letters and skills, if players do not take into account the property status of the word they wish to extend, about one extension in four should originate from the same subject, while three out of four should originate from other subjects. ${ }^{12}$ Higher shares might be expected, however, due to some path dependency causing subjects to find extensions to their own words more easily. Additionally, subjects might think in advance of a stream of extensions when building a root, and hence create a word that they are able to extend by themselves as the game proceeds. Nonetheless, for the sake of simplicity we will take a share of $25 \%$ as our benchmark. Figure 3 gives the average share of extensions built on self-originated words by treatment.

The figure shows that in the noIP treatments the share of self-originated words is near to the $25 \%$ benchmark that we assumed for the case of no preference for own words. In IP treatments, on the other hand, the share is higher than $30 \%$, significantly so with respect to noIP treatments (MWU: for chat/IP and chat/noIP $\mathrm{z}=1.877, \mathrm{p}=.0605$; for noChat/IP and noChat/noIP $\mathrm{z}=2.543, \mathrm{p}=.011)$.

\footnotetext{
${ }^{11}$ Consider, for instance, a four letter word that was created by subject A and then extended by another subject $\mathrm{B}$ : the word is assigned subject A as its originator. This definition strongly simplifies the analysis as we do not have to deal with multiple owners and are still able to make meaningful comparisons based on an appropriate number of observations.

${ }^{12}$ This is the share that should prevail if players do not care about the property of the word they want to extend, and just choose the best option available to them at any time. This is also the expected behavior in the noIP treatments, since in those treatments all words have the same property status - they belong to everyone, and noone.
} 
Figure 3. Share of extensions of self-originated words by treatments (error bars show st.err. of the mean)

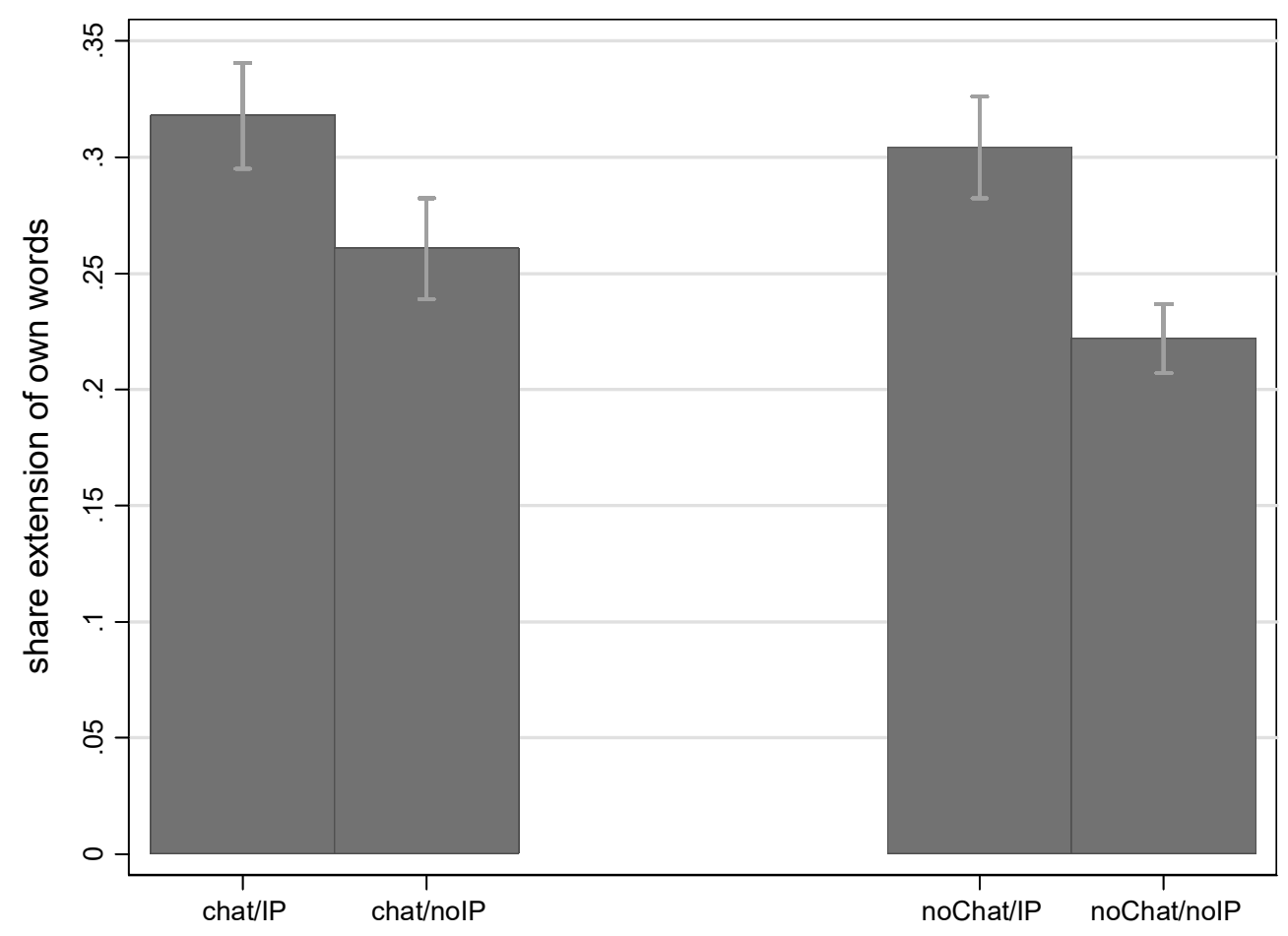

RESULT 2b: The deterioration in welfare due to introducing IP can partially be ascribed to a shift towards favoring self-originated innovations to avoid paying license fees.

\subsubsection{The effect of communication}

When comparing the communication treatments conditional on the IP regime, we find no significant differences in total net value (MWU: for chat/IP and noChat/IP $\mathrm{z}=-0.549$, $\mathrm{p}=.5832$; for chat/noIP and noChat/noIP $\mathrm{z}=-1.444, \mathrm{p}=.1487$ ).

The number of letters bought is significantly higher when there is no chat communication for the noIP treatment (MWU: for chat/IP and noChat/IP $\mathrm{z}=-0.668, \mathrm{p}=.5043$; for chat $/$ noIP and noChat $/$ noIP $\mathrm{z}=-1.852, \mathrm{p}=.0640)$. The difference for $n o I P$ is quite relevant and amounts to 5.5 letters (85.5-80). Without chat communication created words are of the same length (MWU: for chat/noIP and noChat/noIP $\mathrm{z}=-0.808, \mathrm{p}=.4189$; for chat/IP and noChat $/ I P \mathrm{z}=-0.751$, $\mathrm{p}=.4529$ ). The effect of communication on word length is not significant in the $I P$ treatments, while in the noIP case the groups allowed to communicate produce slightly shorter words than the groups that were not (MWU: for $c h a t / n o I P$ and noChat/noIP $\mathrm{z}=-1.877, \mathrm{p}=.0605$; for chat/IP and noChat/IP $\mathrm{z}=-0.866, \mathrm{p}=.3864)$.

These results might be somewhat misleading since not all groups that were offered chat communication actually used it. In chat/IP (chat/noIP) only 58\% (75\%) of groups sent at least 
one message. We can further define a criterion that identifies groups that actually used the chat communication in a meaningful way, i.e., to discuss the game or possible strategies. ${ }^{13}$ Only 42\% (66\%) of the groups in chat/IP (chat/noIP) did so. However, these groups achieved a higher total net value - 219 (263) on average against 167.86 (231.25) on average - than groups that did not use the chat. These differences are only weakly to not significant (MWU: for $I P \mathrm{z}=-1.627, \mathrm{p}=.1038$; for $n o I P \mathrm{z}=-1.189, \mathrm{p}=.2345)$. Recall that in noChat/IP the average created net value amounts to 204.92 and in noChat/noIP to 288.25. Accordingly, groups using chat communication in a meaningful way are still incapable of substantially outperforming the average noChat group. We are further not able to identify whether groups offered communication and using it perform better because of the communication itself or because of a self-selection process, whereby more cooperative or more capable group members communicate more often.

We conclude that introducing communication by no means precludes the detrimental effects of introducing property rights identified in our experiment.

RESULT 3: Allowing for communication has no effect on overall welfare, regardless of the established IP regime.

\subsection{Controlling for the actual choice set}

The results reported above are strong, but are crucially dependent on the path that was taken by the different groups in terms of extendibility of the words created. Each choice by each subject not only gives an immediate payoff, but also shapes the current and future choice sets of all subjects. In this section, we take care of this problem by introducing an indicator of the value of a word relative to the actual choice set facing a subject at the moment of choice.

Consider the actual choice set $C_{i t}$ given for each subject $i$ in period $t$. This choice set is a function of the letters owned by player $i$ and the existing words at time $t$. For each choice $c_{i t} \epsilon C_{i t}$ we computed the immediate net payoff as $\pi\left(c_{i t}\right)$, subtracting from the raw payoffs the license fee paid and the cost of the letter(s) used. We then compute, alongside the actual

\footnotetext{
${ }^{13}$ We define this criterion as being true if players communicate to discuss game related topics and not just greet each other. Communication is defined as game related if they talk about something meaningful with respect to license fees (player 2: “Shall we keep the license fees down?”, player 1: „20 percent is fair :-)”, player 3: „agreed :)", player 4: "Sounds good"), the words produced (player 1: "did you built miste out of mist or out of mit? @ player 2", player 2: "mist"), looking for help to find words (player 2: "do you have an idea for j?", player 1: "hmm, no, that's difficult"), making sure the rules of the experiment (player 3: "How many rounds are there? Till there are no letters left?”, [...] player 1: „25 rounds, I think!“, player 4: „yes“) or discussing possible strategies (player 1: "does it make sense to buy a letter in each round? And we maybe always wait to press enter till the time is over to have more time for thinking?", player 2: "ok").
} 
payoff $\pi_{i t}$ the maximum $M_{i t}=\max \left\{\pi\left(c_{i t}\right), c_{i t} \epsilon C_{i t}\right\}$ and minimum $m_{i t}=\left\{\pi\left(c_{i t}\right), c_{i t} \epsilon C_{i t}\right\}$ payoffs obtainable from $C_{i t}$.

The actual payoff $\pi_{i t}$ is by definition smaller than or equal to the maximum $M_{i t}$ and greater than or equal to the minimum $m_{i t}$ payoff obtainable. We then can calculate the relative net value of the actual choice by subject $i$ at time $t$, henceforth $R N V_{i t}$, as:

$$
R N V_{i t}=\left(\pi_{i t}-m_{i t}\right) /\left(M_{i t}-m_{i t}\right)
$$

Note that $R N V_{i t} \epsilon[0,1], m \leq 0, M \geq 0$ and $m \leq c \leq M$ for all subjects, periods and treatments. This measure allows us to control for path dependency: higher values of the RNV imply better performance in the specific situation conditional on the actual choice set faced by the subject. Subjects clearly should aim to maximize the RNV as it maximizes payoffs. ${ }^{14}$

Table 4 shows the RNV for all treatments pooled over groups and periods.

Table 4. Summary statistics of the Relative Net Value by treatments

\begin{tabular}{lcccc}
\hline & \multicolumn{3}{c}{ RNV } \\
\cline { 2 - 5 } noChat/noIP & average (sd) & median & $\min$ & max \\
\cline { 2 - 5 } & .392 & .387 & .356 & .450 \\
noChat/IP & $.0313)$ & & & .378 \\
chat/noIP & .317 & .311 & .274 & .461 \\
chat/IP & $(.0309)$ & .358 & .272 & .389 \\
& .366 & & & \\
\hline
\end{tabular}

RESULT 1, 2 and 3 are robust to the introduction of RNV rather than total net value. The Null that all RNVs are equal across treatments can be rejected (Kruskal-Wallis test , $\chi^{2}=19.913$ with $\mathrm{df}=3, \mathrm{p}=.0002$ ). We find significant differences between IP treatments conditional on the communication regime (MWU: chat/IP and chat/noIP $\mathrm{z}=-2.136, \mathrm{p}=.0327$; for $n o$ Chat/IP and noChat/noIP $\mathrm{z}=-3.811, \mathrm{p}=.0001$ ), but no significant differences between communication treatments conditional on the IP regime (MWU: chat/IP and noChat/IP $\mathrm{z}=0.520, \mathrm{p}=.6033$; chat/noIP and noChat/noIP $\mathrm{z}=-1.501, \mathrm{p}=.1333)$.

\footnotetext{
${ }^{14}$ Note that, however, using the RNV does not allow for checking if a decision was optimal for the group as a whole. To be capable of defining a decision as being optimal from a group's perspective, we would have to account for all possible paths and future outcomes a root or extension opens up. It is technically possible to do so, but we argue that these calculations are way above the cognitive capabilities of subjects and therefore cannot be considered to measure the optimality of a given choice. Consequently, we build on this rather myopic maximization problem of an individual player.
} 
While the total value created is always weakly increasing over periods, the RNV can in principle increase or decrease. It increases if subjects learn to better exploit the opportunities they face. It decreases if subjects cannot keep up with the increasing amount of possibilities open to them. The maximum obtainable payoff is an indicator of the opportunities that a group is able to build; the RNV measures to what extent these opportunities are seized by the subjects.

Figure 4 shows the development of the maximum, minimum obtainable and actual payoffs over time by treatment.

Figure 4. Evolution of minimum, maximum and actual payoffs by period and treatment

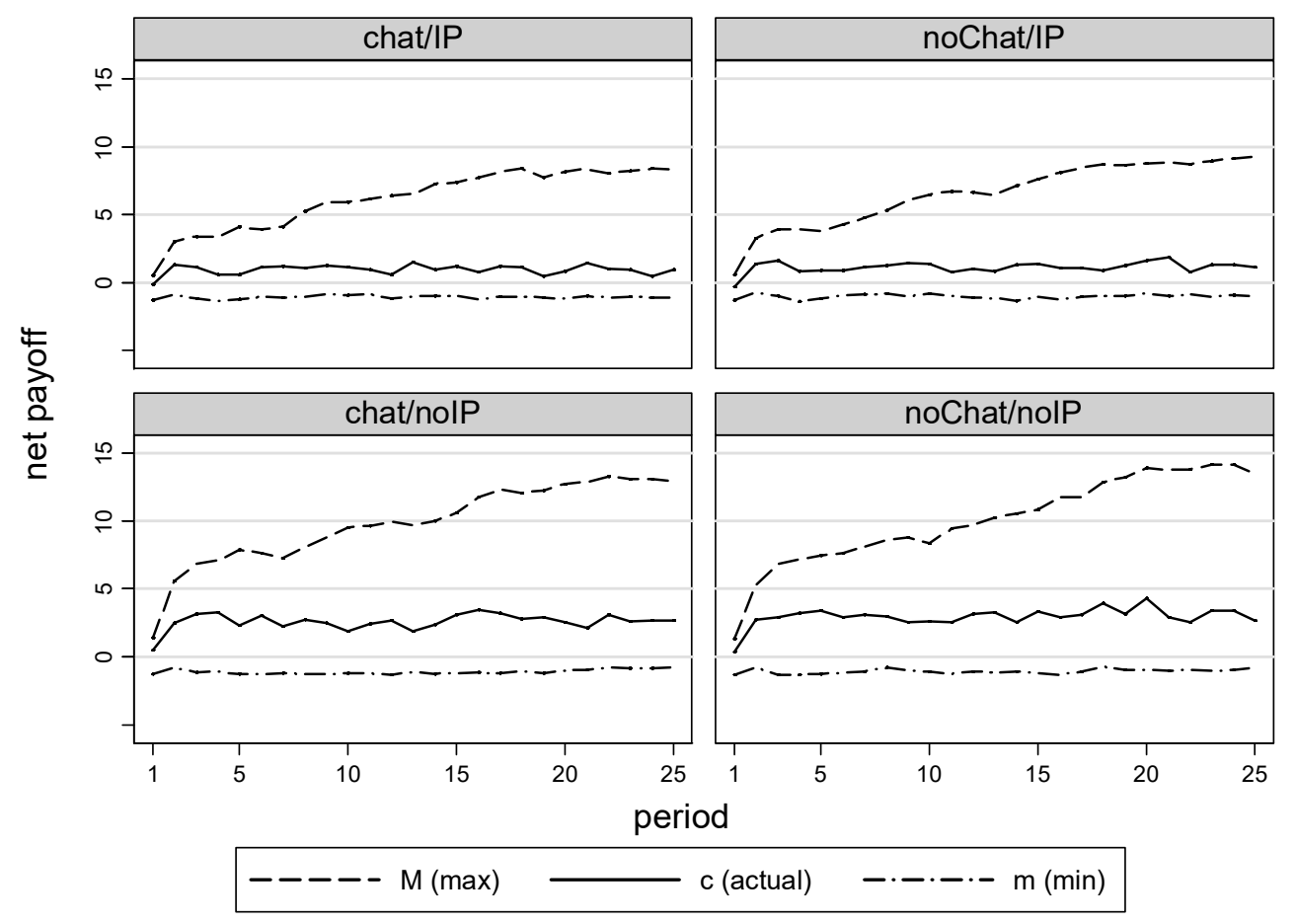

Three remarkable facts are evident from the figure. First, as already noted in table 4 above, the average value of subjects' choices is higher in absence of IP. Second, the RNV is decreasing for all treatments as a consequence of the fact that the increase in $\mathrm{M}$ - as more words are created opening up more opportunities for subjects - is not matched by a similar increase in actual payoffs. Third, noIP treatments generate way more opportunities than $I P$ treatments - as can be seen from the trajectory of the maximum achievable value (M) shooting off. The slope of $\mathrm{M}$ by period is significantly higher for $n o I P$ vs. IP treatments (the slope is 0.4165 for pooled noIP treatments, 0.3069 for pooled $I P$ treatments, significantly different in an interacted regression, $\mathrm{p}<.000$ ). This different success at creating opportunities 
is due to the fact that in noIP treatments more extensions are built, allowing the subjects to reach longer words and opening up a greater set of choices.

In our experiment, in presence of IP some sequential innovations with a very high value for the whole group are not attainable at all or only with considerable delay. For instance, the highest attainable payoff $\mathrm{M}$ reaches in treatment noChat/noIP 10 by period 13, moving then to reach a maximum higher than 14 . In the corresponding noChat/IP treatment, $\mathrm{M}$ is at 6.4 by period 13, and it never reaches the value of 10 .

RESULT 4: In presence of IP valuable sequential innovations are out of reach or achieved with delay only. Absence of IP pushes further the frontier of achievable innovations.

\subsection{Results and behavior determinants at the individual and group level}

We now turn to the individual and group level in order to test the robustness of our results and to identify the determinants of performance.

We run a simple OLS regression of the RNV on treatment conditions and a set of control variables. We introduce dummy variables for chat and IP treatments; their interaction identifies the chat/IP treatment. The baseline treatment for the regression is noChat/noIP. In order to control for unobserved heterogeneity in subjects' abilities in word creation, we include in the regression their performance in the control task that we designed for the purpose and was run before the experiment. Details of the task and its results can be found in appendix A. We include dummy variables for subjects in the upper and lower 25 percentile of the earned points distribution in the task, denoted as wordtask_high and wordtask_low. Furthermore age, female, proficiency in German (on a scale from 1 to 5) and period are included as explanatory variables. We interact period with the respective treatment condition, as we expect the RNV to decrease more strongly in absence of property rights (see figure 4). Individuals' performance might crucially depend on the capabilities of the other group members. We therefore run the regression on the group level as well. In this case the most capable member of the group might determine the others' performance as she might open up promising paths by building favorable roots and extensions. The exact opposite might be true if there is a member with very low task-specific skills. This aspect is accounted for by redefining the dummy variables wordtask_high and wordtask_low, which in this case refer to the presence of at least one group member showing high or low performance in the control task. Results are summarized in table 5. 
Table 5. Regression results - RNV

\begin{tabular}{|c|c|c|}
\hline & (individual level) & (group level) \\
\hline chat & $\begin{array}{l}-\mathbf{- 0 . 0 3 2 5} \\
(0.0321)\end{array}$ & $\begin{array}{l}\mathbf{- 0 . 0 4 1 9} \\
(0.0297)\end{array}$ \\
\hline IP & $\begin{array}{c}-\mathbf{0 . 0 8 3 9} * * \\
(0.0346)\end{array}$ & $\begin{array}{c}-\mathbf{0 . 0 8 7 1} * * * \\
(0.0297)\end{array}$ \\
\hline chat_IP & $\begin{array}{c}\mathbf{0 . 0 6 5 3} \\
(0.0534)\end{array}$ & $\begin{array}{l}\text { 0.0794* } \\
(0.0420)\end{array}$ \\
\hline period & $\begin{array}{c}-\mathbf{- 0 . 0 1 1 2} * * * * \\
(0.00145)\end{array}$ & $\begin{array}{c}-\mathbf{0 . 0 1 1 8 * * *} \\
(0.00141)\end{array}$ \\
\hline period_chat/IP & $\begin{array}{c}-\mathbf{- 0 . 0 0 1 3 5} \\
(0.00265)\end{array}$ & $\begin{array}{l}\mathbf{- 0 . 0 0 1 7 9} \\
(0.00199)\end{array}$ \\
\hline period_noChat/IP & $\begin{array}{l}\mathbf{0 . 0 0 0 2 8 1} \\
(0.00208)\end{array}$ & $\begin{array}{l}\mathbf{0 . 0 0 0 6 0 1} \\
(0.00199)\end{array}$ \\
\hline period_chat/noIP & $\begin{array}{l}\mathbf{0 . 0 0 0 6 4 9} \\
(0.00234)\end{array}$ & $\begin{array}{c}\mathbf{0 . 0 0 0 8 6 2} \\
(0.00199)\end{array}$ \\
\hline high in control task & $\begin{array}{c}\mathbf{0 . 0 1 7 1} \\
(0.0170)\end{array}$ & $\begin{array}{c}\mathbf{0 . 0 1 4 5} \\
(0.0110)\end{array}$ \\
\hline low in control task & $\begin{array}{c}-\mathbf{- 0 . 0 5 7 0} * * * * \\
(0.0163)\end{array}$ & $\begin{array}{l}-\mathbf{- 0 . 0 1 0 2} \\
(0.0115)\end{array}$ \\
\hline female & $\begin{array}{c}-\mathbf{0 . 0 2 5 9} * * \\
(0.0123)\end{array}$ & \\
\hline age & $\begin{array}{c}-\mathbf{0 . 0 0 4 9 1 * *} \\
(0.00233)\end{array}$ & \\
\hline proficiency & $\begin{array}{c}\mathbf{0 . 0 0 2 3 8} \\
(0.00408)\end{array}$ & \\
\hline Constant & $\begin{array}{c}\mathbf{0 . 6 7 3} * * * \\
(0.0608)\end{array}$ & $\begin{array}{c}\mathbf{0 . 5 5 2} * * * \\
(0.0246)\end{array}$ \\
\hline Observations & 4603 & 1200 \\
\hline R-squared & 0.070 & 0.216 \\
\hline
\end{tabular}

Note: Standard errors in parentheses and ${ }^{* * *} \mathrm{p}<0.01,{ }^{* *} \mathrm{p}<0.05,{ }^{*} \mathrm{p}<0.1$. Standard errors are clustered on the group level for the individual level regression.

Estimated coefficients confirm our findings. Introducing IP decreases the relative net value. A joint significance test for chat and chat_IP does not reject the Null of no influence (on the individual level $\mathrm{F}=.81, \mathrm{p}=.4502$; on the group level $\mathrm{F}=1.8, \mathrm{p}=.1662$ ). Thus chat communication cannot prevent the negative effect of introducing intellectual property rights. As the game proceeds, created relative net value deteriorates as the marginal effect for period is significant, negative and quite strong. Recall that 25 periods were played, i.e. the average RNV is estimated to almost halve from the first to the last period. This result confirms the developments shown in figure 4, although the interaction of period and $I P$ is not significant, indicating that there is no significant difference in the downward trend between treatments. The indicator variables for the performance in the control task show the expected signs. On the individual level we find a significantly worse performance of subjects performing weakly 
in our control task. Females and older participants tend to perform worse, while the selfreported level of proficiency in German shows no significant influence.

All in all, our results prove robust when controlling for the dynamics of the game, the actual choice set and participants characteristics at the individual and group level.

The results of the RNV regressions shed light on another reason why IP leads to comparatively worse performance: in IP treatments subjects restrict attention to selforiginated words more than what optimal behavior would grant. In presence of license fees, optimality for the individual and for the group diverge. Roots and extensions of own words are more favorable as no license fee payments are induced. Thus, the observed systematic shift in behavior towards more roots and more self-originated words could reflect a rational, payoff-maximizing adjustment at the individual level. The RNV regressions show that this is not the case. In IP treatments subjects not only create less opportunities (lower maximum available payoff, see figure 4), but they also perform worse relative to these reduced opportunities, as clearly indicated by the strong and significantly negative effect for $I P$ in the RNV regressions. In IP treatments subjects overreact to the introduction of IP and forego substantial gains by trying to avoid license fee payments. As a consequence the total value created decreases even more than it could be expected when assuming fully rational behavior.

RESULT 5: IP causes behavior to change even more drastically than it could be expected by assuming rational behavior. Subjects opt for lower net payments to avoid license fees.

\subsection{Dynamics of license fees}

In $I P$ treatments subjects were able to choose the license fee between 0 and $100 \%$ of the value of their marginal contribution to the word. Figure 5 shows the average license fees chosen over periods for the $I P$ treatments. Average fees tend to increase as the game proceeds. ${ }^{15}$ Since the chosen fee can be interpreted as a measure of the level of cooperation within a group (cooperation increases as the fee demanded goes down), this finding resembles the typical pattern of social interaction shown in many public good experiments (see, for instance, Fischbacher and Gächter, 2010). In the first five periods, the average fee amounts to 0.59 (0.49) in chat/IP (noChat/IP); it increases to 0.69 (0.63) in the last five periods. Overall, the presence of communication does not seem to avoid deteriorating cooperation levels; overall

\footnotetext{
${ }^{15}$ Although the result of increasing license fees is not generalizable as subjects knew the finite horizon of 25 periods, it is an interesting finding which well connects to the findings in public goods experiments, see Ostrom (2000)
} 
fee levels are not significantly different between chat/IP and noChat/IP (MWU, z=.924, $\mathrm{p}=.3556){ }^{16}$

Figure 5. Average license fees over periods by treatment and within chat/IP
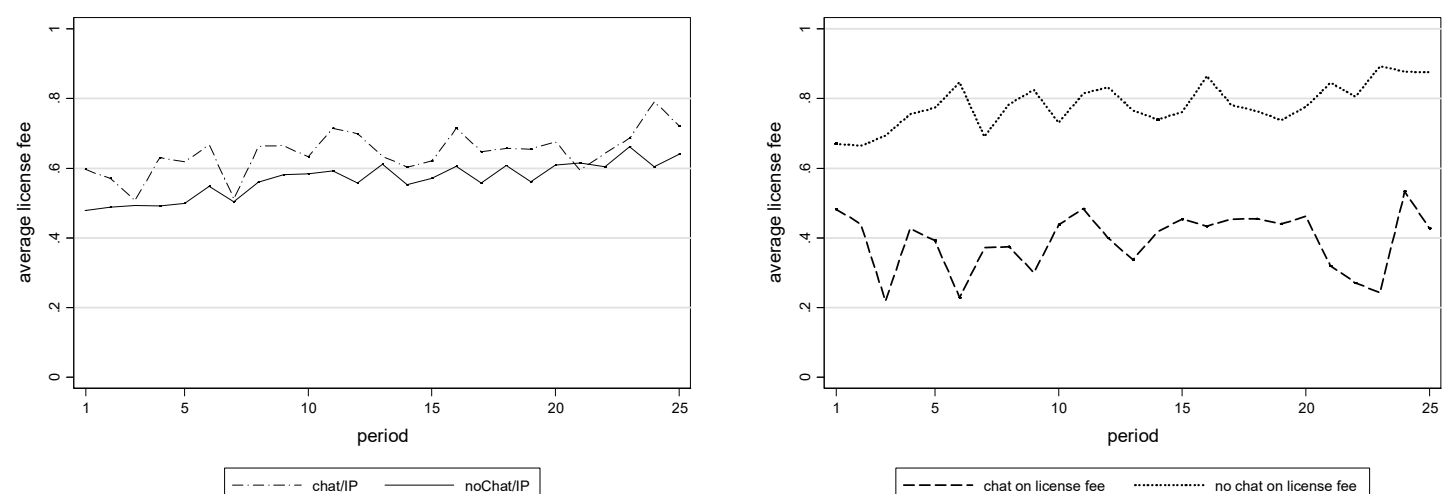

We additionally distinguish groups that use chat communication to discuss license fee levels from those that do not. ${ }^{17}$ In line with results in the public good game literature, the former tend to be able to maintain lower fees over the course of the experiment. Communicating groups start off at low fees, and are able to avoid a deterioration of cooperation. Observing group members that refrain from communication might be interpreted as a strong statement for the unwillingness to cooperate in general, which then leads to higher fees in comparison to treatments in which there is no opportunity to communicate in the first place. However, this difference within the chat/IP treatment might be due to self-selection. The difference cannot be held as evidence in support of a positive communication effect.

Overall, we conclude that for most groups chat communication is not used to solve the collective action problem more pronounced in presence of $I P$. Restricting the analyses to the groups actually coordinating on low fees, we observe no impact of the chat manipulation on innovation and welfare levels.

This surprising result is due to the absence of correlation between the average level of license fees in a group and value created. One might expect performance to be inversely correlated to the prevailing fees, and groups agreeing upon low fees to perform in a similar way to the ones acting in absence of IP. This is not the case. Figure 6 plots, for each group, average fee levels against achieved welfare as measured by total net value.

\footnotetext{
${ }^{16}$ Increasing license fees are not due to more extensions being built as the game proceeds. In fact, for both $I P$ treatments license fees tend to be lower for extensions (chat/IP for the first half of the game $\mathrm{m}=.61, \mathrm{sd}=.28$ and for the second half $\mathrm{m}=.65, \mathrm{sd}=.29$; noChat/IP for the first half $\mathrm{m}=.50, \mathrm{sd}=.20$ and for the second half $\mathrm{m}=.57$, $\mathrm{sd}=.24)$ in comparison to roots (chat/IP for the first half of the game $\mathrm{m}=.66, \mathrm{sd}=.58$ and for the second half $\mathrm{m}=.71, \mathrm{sd}=.29 ;$ noChat $/ I P$ for the first half $\mathrm{m}=.58, \mathrm{sd}=.22$ and for the second half $\mathrm{m}=.65, \mathrm{sd}=.23$ ).

${ }^{17}$ Out of 12 groups in chat/IP only 5 groups actually used chat communication and only 4 specifically discussed the levels of license fees to choose.
} 
Figure 6. Average license fees and total net value

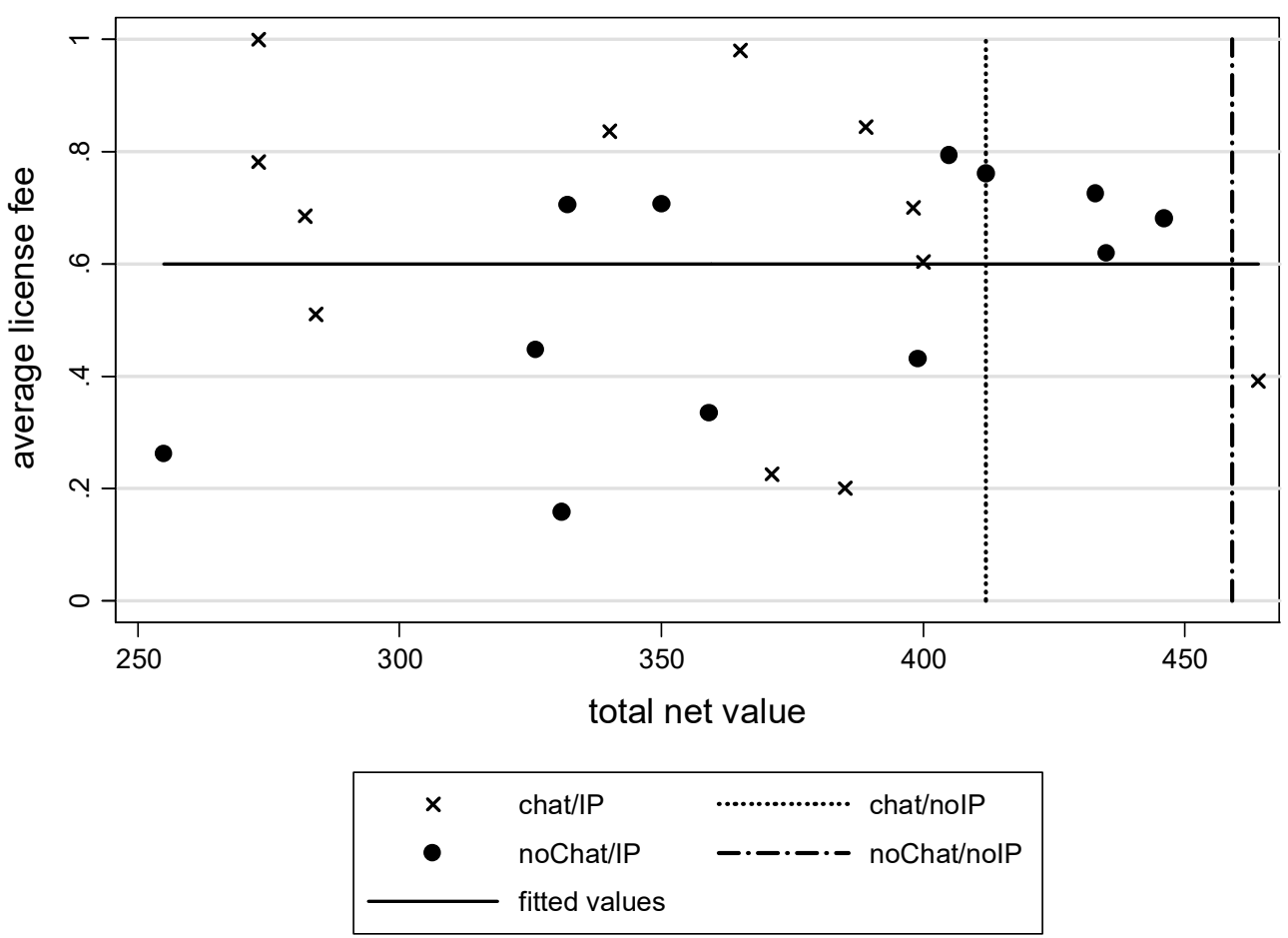

While there seems to be a weak and non-significant negative correlation of fee levels and total net value when there is chat communication, this relationship is reversed without communication. Pooling together both $I P$ treatments gives a correlation of average license fee and total value created that is close to and indistinguishable from $0 \quad(\rho<-0.0000)$. Endogenously chosen fee levels are hence not systematically related with the group's total output. We conclude that introducing an IP regime has a negative effect per se: the absolute levels of license fees are irrelevant.

RESULT 6: License fees tend to increase over time; groups effectively using the chat display lower and stable fee levels, but those are of no importance for the detrimental effect of an IP regime.

\section{Conclusion}

This paper contributes to the debate on the role of intellectual property rights by means of a laboratory experiment. We recreate in the laboratory a sequential innovation environment, and use a word-creation task that combines the central features of innovation, investment and creativity, in one experiment. We use this task to investigate the effects of the presence or absence of intellectual property rights on innovation activity and welfare. We further assess the effect of communication with and without IP. 
Results clearly show that the introduction of intellectual property hinders innovation. In presence of IP the economy produces less valuable innovations, and welfare decreases. Introducing IP causes a shift towards more basic innovations and a higher degree of autarky i.e., relying on the self-produced prior innovations rather than building on the best available opportunity within the economy at large. Conversely, the absence of IP results in more sophisticated and more valuable innovations and provides incentives to stand on the shoulders of giants, opening up more profitable innovation paths. Moreover, the negative effects of IP are not a short term phenomenon, but rather worsen over time as license fees tend to increase, leading to the breakdown of cooperative efforts and the use of autarkic strategies.

These results are robust to the introduction of communication. The possibility to cooperate directly via chat, i.e. the possibility to negotiate a mutually beneficial level of license fees, is only seldom exploited, and if so, it does not lead to increased levels of innovation and welfare.

Our experimental approach gives us distinct control over confounding factors, and produces clean causal evidence. At the same time, the validity of results from the lab for actual field conditions might be questioned. Therefore, we chose a task that included several features of real innovations - the sequential nature, the intrinsic plus the potential value of innovations, the role of creativity, knowledge, cooperation, competition, and skill, the presence of risky investments -, that were at the same time intuitive for subjects and completely controllable by the experimenters. To the extent that the characteristics of our task match the ones of actual innovation industries our results can be applied also outside the laboratory.

Our results suggest that in industries where innovations are strongly sequential - as in pharmaceutical, bioengineering, and software industries - granting intellectual property rights might slow down the rate of innovation and reduce welfare. Thus, our findings lend support to the arguments against the extension of intellectual property to new fields, especially if they are characterized by fast, frequent, small and cumulative innovations - as is the case of software patents. Our findings are in line with insights from the model of Bessen and Maskin (2009) and the case against IP made by Boldrin and Levine (2013).

In our experiment both innovation and welfare thrive without IP, as it happened to several industries in the past, and are hampered by the presence of intellectual property rights, whose stated reason to exist is, paradoxically, to foster innovation. 
Acknowledgement: Financial support for conducting the laboratory experiments from the German Federal Ministry of Education and Research and the German Aerospace Center is gratefully acknowledged (Grant number 01UN1014A).

\section{References}

Aghion, P., Bloom, N., Blundell, R., Griffith, R., Howitt, P., 2005. Competition and innovation: An inverted-U relationship. The Quarterly Journal of Economics 120 (2), 701728.

Arrow, K.J., 1962. Economic welfare and the allocation of resources for invention, in: Nelson, R.R. (Ed), The rate and direction of inventive activity. Economic and social factors. Princeton University Press, Princeton, NJ, pp. 609-626.

Bessen, J., Maskin, E., 2009. Sequential innovation, patents, and imitation. The RAND Journal of Economics 40 (4), 611-635.

Bessen, J., Meurer, M.J., 2008. Do patents perform like property? Academy of Management Perspectives $22(3), 8-20$.

Bochet, O., Page, T., Putterman, L., 2006. Communication and punishment in voluntary contribution experiments. Journal of Economic Behavior \& Organization 60 (1), 11-26.

Boldrin, M., Levine, D.K., 2008. Perfectly competitive innovation. Journal of Monetary Economics 55 (3), 435-453.

Boldrin, M., Levine, D.K., 2013. The case against patents. The Journal of Economic Perspectives 27 (1), 3-22.

Buccafusco, C., Sprigman, C., 2010. Valuing intellectual property: An experiment. Cornell Law Review 96 (1), 1-46.

Buchanan, J.A., Wilson, B.J., 2014. An experiment on protecting intellectual property. Experimental Economics 17 (4), 691-716.

Cantner, U., Güth, W., Nicklisch, A., Weiland, T., 2009. Competition in product design: An experiment exploring innovation behavior. Metroeconomica 60 (4), 724-752.

Crosetto, P., 2010. To Patent or not to Patent: A pilot experiment on incentives to copyright in a sequential innovation setting, in: Ågerfalk, P.J., Boldyreff, C., González-Barahona, J.M., Madey, G.R., Noll, J. (Eds), Open source software. New horizons. 6th International IFIP WG 2.13 Conference on Open Source Systems. Springer, Berlin, New York, pp. 53-72.

Croson, R.T., 2007. Theories of commitment, altruism and reciprocity: Evidence from linear public goods games. Economic Inquiry 45 (2), 199-216. 
Denicolò, V., 2008. Ecomonic theories of the nonobviousness requirement for patentability: A survey. Lewis \& Clark Law Review 12 (2), 443-459.

Dimmig, A.-K., Erlei, M., 2013. Quasi-rational R\&D behavior in an environment with fundamental uncertainty. TUC Working Papers in Economics 0008.

Dosi, G., Marengo, L., Pasquali, C., 2006. How much should society fuel the greed of innovators?: On the relations between appropriability, opportunities and rates of innovation. Research Policy 35 (8), 1110-1121.

Eckartz, K., Kirchkamp, O., Schunk, D., 2012. How do incentives affect creativity? CESifo Working Paper 4049.

Ederer, F., Manso, G., 2013. Is pay-for-performance detrimental to innovation? Management Science 59 (7), 1496-1513.

Ernst, H., 2001. Patent applications and subsequent changes of performance: Evidence from time-series cross-section analyses on the firm level. Research Policy 30 (1), 143-157.

Fershtman, C., Markovich, S., 2010. Patents, imitation and licensing in an asymmetric dynamic R\&D race. International Journal of Industrial Organization 28 (2), 113-126.

Fischbacher, U., Gächter, S., 2010. Social preferences, beliefs, and the dynamics of free riding in public goods experiments. The American Economic Review 100 (1), 541-556.

Furukawa, Y., 2007. The protection of intellectual property rights and endogenous growth: Is stronger always better? Journal of Economic Dynamics and Control 31 (11), 3644-3670.

Gallini, N.T., Scotchmer, S., 2002. Intellectual property: When is it the best incentive system?, in: Jaffe, A.B., Lerner, J., Stern, S. (Eds), Innovation policy and the economy, vol. 2. MIT Press, Chicago, pp. 51-77.

Green, J.R., Scotchmer, S., 1995. On the division of profit in sequential innovation. The RAND Journal of Economics 26 (1), 20-33.

Greiner, B., 2004. An online recruitment system for economic experiments, in: Kremer, K., Macho, V. (Eds), Forschung und wissenschaftliches Rechnen, Göttingen, pp. 79-93.

Hall, B.H., Harhoff, D., 2012. Recent research on the economics of patents. Annual Review of Economics 4, 541-565.

Hall, B.H., Jaffe, A.B., Trajtenberg, M., 2005. Market value and patent citations. The RAND Journal of Economics 36 (1), 16-38.

Hashmi, A.R., 2013. Competition and innovation: The inverted-U relationship revisited. The Review of Economics and Statistics 95 (5), 1653-1668.

Heller, M.A., Eisenberg, R.S., 1998. Can patents deter innovation?: The anticommons in biomedical research. Science 280 (5364), 698-704. 
Hunt, R.M., 2004. Patentability, industry structure, and innovation. The Journal of Industrial Economics 52 (3), 401-425.

Jaffe, A.B., 2000. The U.S. patent system in transition: Policy innovation and the innovation process. Research Policy 29 (4), 531-557.

Kirchkamp, O., Reiß, J.P., 2011. Out-of-equilibrium bids in first-price auctions: Wrong expectations or wrong bids. The Economic Journal 121 (557), 1361-1397.

Krishnamurthy, S., 2001. Communication effects in public good games with and without provision points, in: Isaac, R.M., Norton, D.A. (Eds), Research in experimental economics. Emerald, Bingley, U.K, pp. 25-46.

Lakhani, K.R., Hippel, E. von, 2003. How open source software works: "Free" user-to-user assistance. Research Policy 32 (6), 923-943.

Lanjouw, J.O., Lerner, J., 2000. The enforcement of intellectual property rights: A survey of the empirical literature, in: Encaoua, D., Hall, B.H., Laisney, F., Mairesse, J. (Eds), The economics and econometrics of innovation. Springer, Boston, MA, pp. 201-224.

Lerner, J., 2009. The empirical impact of intellectual property rights on innovation: Puzzles and clues. The American Economic Review 99 (2), 343-348.

Machlup, F., 1958. An economic review of the patent system. Study of the Subcommittee on Patents, Trademarks and Copyrights of the Committee on the Judiciary 15. U.S. Congress. Government Printing Office, Washington, DC.

Meloso, D., Copic, J., Bossaerts, P., 2009. Promoting intellectual discovery: Patents versus markets. Science 323 (5919), 1335-1339.

Moschini, G., Yerokhin, O., 2008. Patents, research exemption, and the incentive for sequential innovation. Journal of Economics \& Management Strategy 17 (2), 379-412.

Nordhaus, W.D., 1969. Invention, growth and welfare: A theoretical treatment of technological change. MIT Press, Cambridge, MA.

Oprea, R., Charness, G., Friedman, D., 2014. Continuous time and communication in a public-goods experiment. Journal of Economic Behavior \& Organization 108, 212-223.

Ostrom, E., 2000. Collective action and the evolution of social norms. The Journal of Economic Perspectives 14 (3), 137-158.

Qian, Y., 2007. Do national patent laws stimulate domestic innovation in a global patenting environment?: A cross-country analysis of pharmaceutical patent protection, 1978-2002. The Review of Economics and Statistics 89 (3), 436-453.

Scherer, F.M., 1972. Nordhaus' theory of optimal patent life: A geometric reinterpretation. The American Economic Review 62 (3), 422-427. 
Scotchmer, S., 1991. Standing on the shoulders of giants: Cumulative research and the patent law. The Journal of Economic Perspectives 5 (1), 29-41.

Scotchmer, S., 2004. Innovation and Incentives. MIT Press, Cambridge, MA.

Sørensen, F., Mattson, J., Sundbo, J., 2010. Experimental methods in innovation research. Research Policy 39 (3), 313-323.

Stiglitz, J.E., 2008. Economic foundations of intellectual property rights. Duke Law Journal 57 (6), 1693-1724.

Toubia, O., 2006. Idea generation, creativity, and incentives. Marketing Science 25 (5), 411425.

Williams, H.L., 2013. Intellectual property rights and innovation: Evidence from the human genome. Journal of Political Economy 121 (1), 1-27. 


\section{Appendix A - Performance in the control task}

Before starting the experiment, we ran a control task to measure the subjects' word-creation abilities, with the aim of creating a variable to control for skill heterogeneity in our regression analysis. The control task is built on Eckartz et al. (2012). All subjects are endowed with the same alphabetically ordered set of 12 letters (accehhikllst), and have 3 minutes to build as many words as possible, using only letters from the set. Each word earns the subject points. The value of the words created increases more than proportionally in length: a three-letter word yields 6 points, a four-letter words 10, a five-letter word 15, etc. In total, the given letter set allows to build 330 words, worth 5585 points. ${ }^{18}$ The task is incentivized by rewarding the performance of the best three subjects in each session with $€ 1$. Figure A.1 gives an overview of the distribution of the groups' performance across treatments as measured by points earned.

Figure A.1. Performance in the control task by group and treatment

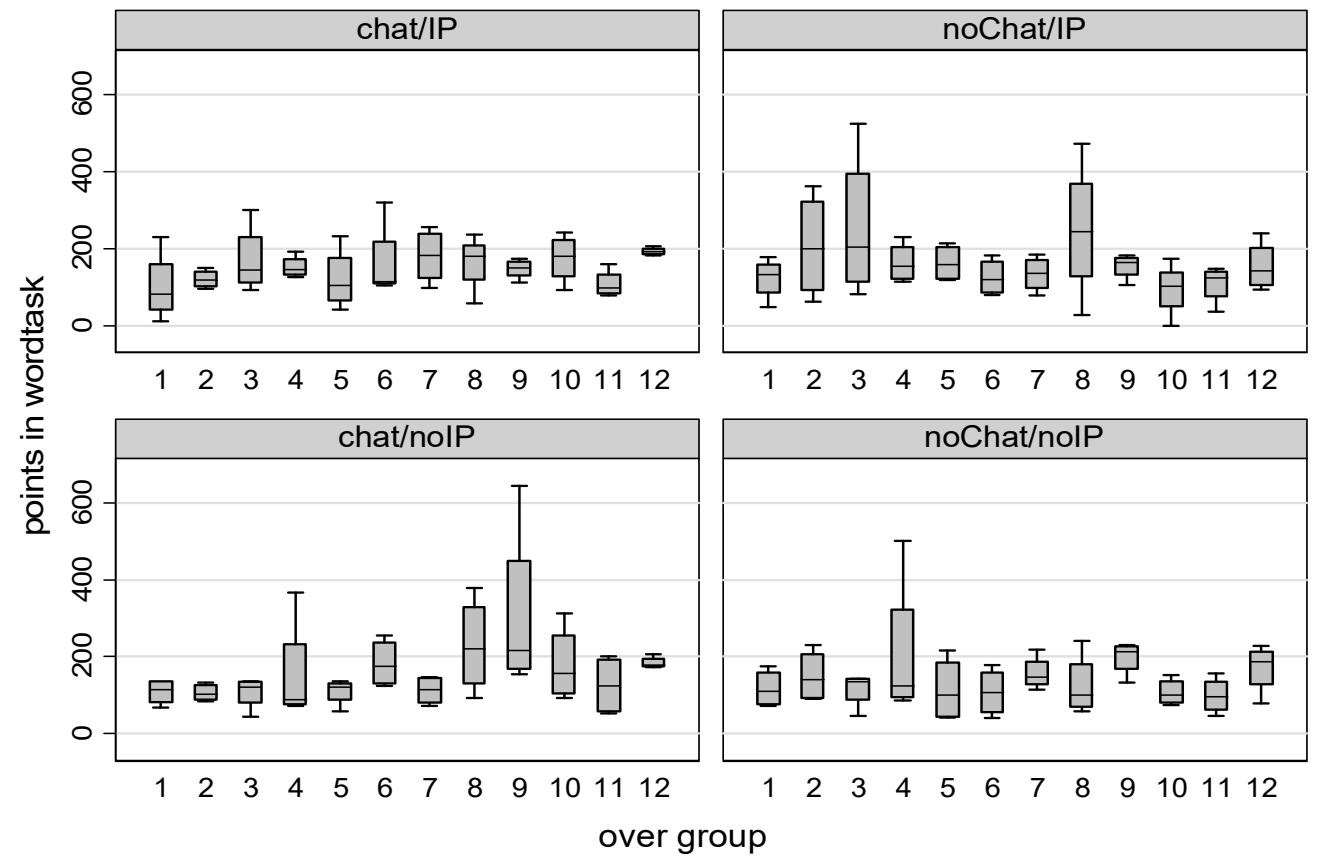

While there is some heterogeneity on the group level, differences equal out at the treatment level. Applying a Kruskal-Wallis test on the group level, we fail to reject the Null of equal performance across treatments $\left(\chi^{2}=1.021\right.$ with $\left.\mathrm{df}=3, \mathrm{p}=0.7962\right)$. Overall, our groups do not statistically differ in word-creation skills across treatments. Individuals' differences in the control task are used to control for individual skills in the regressions of section 3.3.

${ }^{18}$ The instructions for the control task can be found in appendix $\mathrm{C}$. 


\section{Appendix B - Instructions}

We report here the English translation of the original German instructions for all treatments. The differences between treatments are indicated in square brackets. The original German instructions are available upon request.

\section{The Game}

In this experiment, your task is to build words out of letters as in the board game "Scrabble". By building words you increase your payoff: For each word you get a payoff calculated by the sum of the values of each letter. You start the game with an endowment of 4 letters. During the course of the game, you are able to buy additional letters.

During the course of the game, you will play in a group of 4 players [chat treatments: with whom you are able to chat].

\section{Payoffs}

Your payoff depends on the sum of the value of your letters, which is calculated in experimental tokens. One token is converted to 0.12 Euro at the end of the experiment. You start the game with an endowment of 75 tokens. Note that it is possible to end the experiment with less than your starting endowment.

Please note the table below containing all letters, their value (in tokens) and the frequency with which they occur in the game. During the game the letters are always displayed along with their value.

\section{Table 1: List of letters}

\begin{tabular}{|c|c|c|c|c|c|c|c|c|}
\hline Letter & Value & Frequency & Letter & Value & Frequency & Letter & Value & Frequency \\
\hline $\mathrm{A}$ & 1 & 10 & $\mathrm{~J}$ & 6 & 2 & $\mathrm{~S}$ & 1 & 14 \\
\hline $\mathrm{B}$ & 3 & 4 & $\mathrm{~K}$ & 4 & 4 & $\mathrm{~T}$ & 1 & 12 \\
\hline $\mathrm{C}$ & 4 & 4 & $\mathrm{~L}$ & 2 & 6 & $\mathrm{U}$ & 1 & 12 \\
\hline $\mathrm{D}$ & 1 & 8 & $\mathrm{M}$ & 3 & 8 & $\mathrm{~V}$ & 6 & 2 \\
\hline $\mathrm{E}$ & 1 & 30 & $\mathrm{~N}$ & 1 & 18 & $\mathrm{~W}$ & 3 & 2 \\
\hline $\mathrm{F}$ & 4 & 4 & $\mathrm{O}$ & 2 & 6 & $\mathrm{X}$ & 8 & 2 \\
\hline $\mathrm{G}$ & 2 & 6 & $\mathrm{P}$ & 4 & 2 & $\mathrm{Y}$ & 10 & 2 \\
\hline $\mathrm{H}$ & 2 & 8 & $\mathrm{Q}$ & 10 & 2 & $\mathrm{Z}$ & 3 & 2 \\
\hline $\mathrm{I}$ & 1 & 12 & $\mathrm{R}$ & 1 & 12 & & & \\
\hline
\end{tabular}

On the next page you will find a screenshot of the main board of the game and some explanations to get a first overview of the game. A detailed explanation of the game ensues. 


\section{General view on the main board}

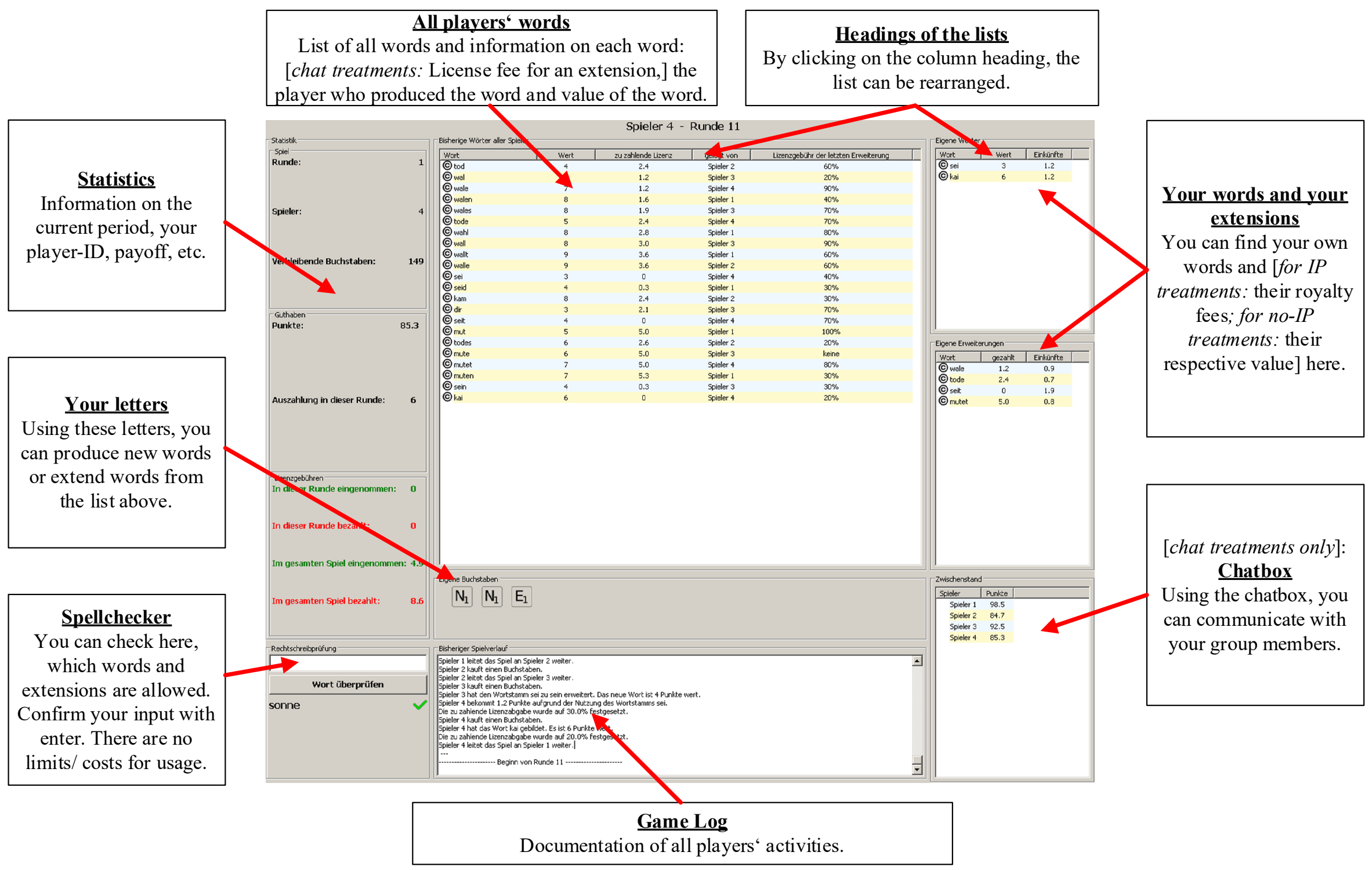




\section{Course of a turn}

When it is your turn, a dialog pops up asking you for choices. During your turn you cannot use the spellchecker [chat treatments: and the chat]. You have 45 seconds for your decisions. You can see the remaining time on the top-left corner of the screen. If your time expires, you are subtracted 1 token for every additional 10 seconds from your endowment.

Every turn consists of two phases [IP treatments: three phases]:

\section{Buying phase}

\section{Your activity: Buying letters}

You can choose to buy or not to buy one letter at the price of 2 tokens. If you buy a letter, it will be chosen randomly from the list of letters shown on the table on page 1. At the beginning you are given four letters for free. Each letter can only be used once: After producing or extending a word the letter will be deleted from your letter set.

\section{Word phase}

\section{Your activity: Producing or extending words}

You can use German words, their conjugations and declinations and some names of places and persons. You can test if a word is correct using the spellchecker when it is not your turn. Correct words can be built as follows:

\section{Option 1: Producing a 3-letter word}

a) You can produce a word using exactly three of your letters. The payoff you earn for creating a word is given by the sum of the value of the letters (Example: ,pol': $\mathrm{p}=4, \mathrm{o}=2,1=2$. This results in $4+2+2=8$ tokens).

To create a word, you will have to type in the letters with your keyboard.

Please note that you cannot undo mistakes: if you make an error while inputting the word (i.e. inputting a too long, too short, nonexistent or misspelled word, or pressing the enter key on an empty field) the turn passes to the next player. You will have the opportunity to reiterate your entry correctly only in the next period, during your next turn.

\section{Option 2: $\quad$ Extending a word}

b) You can extend an existing word inserting one letter in any position in the word. For example 'ast' can be extended into 'last', 'rast' and 'aste'. And 'last' again into 'laust' and this into 'klaust'. It is not possible to rearrange existing words (e.g. to build from 'ast' the word 'Star').

Your payoff results from the sum of the value of the letters of the newly extended word. By extending e.g. 'last' into 'laust' you get $1=2, a=1, u=1, s=1, t=1$, so $2+1+1+1+1=6$ tokens. Every word can only be produced once but can subsequently be used for as many extensions as possible. 
c) In case you are not able to produce nor to extend any word, you can pass the turn to the next player.

\section{License phase [IP treatments only]}

\section{Your activity: Setting a license fee}

After producing a word you have to set a license fee which other players are required to pay when creating extensions. The fee must be set between 0 and 100 percent of the value of the word.

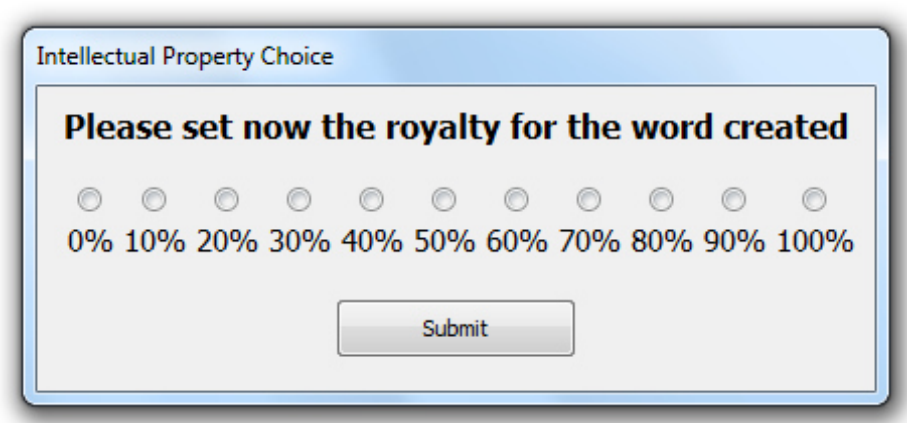

If another player extends your word, he automatically transfers the fee to you.

- 0 percent means that the word is entirely free for other players.

- At 100 percent, the next player only receives the value of his added letter.

- The choice of 20 percent means that the respective player has to pay 20 percent of the value of the word to you.

The license fee for a word remains fixed during the entire game. The word appears on the list of public words on the main board and can be used by everyone. However, other players have to pay the license fee when extending the word.

Furthermore, you will have to set a license fee if you extend a word with one letter. In this case, you decide on the fee only for your added letter. Your payoff results from the sum of the value of all letters minus the license fee for the word you built on.

After that, your turn ends and it is the next player's turn. The game is played for 25 periods. Finally, for clarification, some payoff-examples are offered:

\section{Examples for potential payoffs [IP treatments]:}

Example 1: If player 1 sets a license fee of 90 percent for the word 'ast' (value of the word 3 tokens: $\mathrm{a}=1, \mathrm{~s}=1, \mathrm{t}=1$ ) and player 2 extends the word into 'hast' (value of $\mathrm{h}=2$ ), this results in the following payoffs:

Player 1: 90 percent of 3 tokens $=2.7$ tokens (license fee for player 1 )

Player 2: $3-2.7$ tokens (to player 1 ) +2 tokens for the letter ' $h$ ' $=0.3$ tokens +2 tokens $=2.3$ tokens 
Example 2: If player 1 sets the license fee of 0 percent for 'ast', player 2 receives the sum of the value of all letters for extending it into 'hast':

Player 1: 0 percent of 3 tokens $=0$ token

Player 2: 100 percent of 5 tokens $=5$ tokens

Example 3: After extending a word, the player has to set a license fee for the added letter. Player 1 sets a license fee of 10 percent for 'ast' and player 2 sets a license fee of 50 percent for the letter ' $h$ ' in 'hast'. If player 3 then extends 'hast' into 'haust', this results in the following payoffs:

Player 1: 10 percent of 3 tokens $=0.3$ (license fee for player 1$)$

Player 2: 50 percent of 2 tokens $=1$ (license fee for player 2)

Player 3: 6 tokens for ,haust ${ }^{\star}-0.3$ tokens (to player 1) -1 token (to player 2$)=4.7$ tokens

\section{Examples for potential payoffs [no-IP treatments]:}

Example 1: Player 1 produces the word 'ast'. The values of the letters are $a=1$ token, $s=1$ token, $\mathrm{t}=1$ token. Therefore, he gets $1+1+1=3$ tokens for his word.

Example 2: If player 2 extends 'ast' into 'hast', he will get 5 tokens, as all values of letters of the word ( $\mathrm{h}=2$ tokens, $\mathrm{a}=1$ token, $\mathrm{s}=1$ token, $\mathrm{t}=1$ token) will be added: $2+1+1+1=5$ tokens.

\section{Appendix C - Instructions for the control task}

Note: The instructions for the word task were shown on screen.

In the next screen you will see a string composed of 9 letters.

You will be asked to create as many German words as possible using these letters within 3 minutes.

You can type the words you create in the field beneath the string of 9 letters, and you submit them by hitting Enter.

You can use each letter only once per word and a word cannot be shorter than 3 letters.

Longer words generate more points.

3-letter-word: $3+2+1=6$ points

4-letter-word: $4+3+2+1=10$ points

etc.

After the 3 minutes will have expired, the test will end and you will be shown your results.

As soon as you enter the next screen, the timer will start ticking.

To go to the next screen, please press the letter ' $R$ ' on your keyboard. 